\title{
Valuing a Multi-Zone Mine as a Real Asset Portfolio - A Modern Asset Pricing (Real Options) Approach
}

\author{
Michael Samis, Ph.D. \\ 86 Silo Circle \\ Riverside, CT \\ USA, 06878-1114 \\ msamis@attglobal.net
}

\begin{abstract}
Modern asset pricing (MAP; commonly known as real options valuation) has been used as an alternative to discounted cash flow (DCF) methods in the mining industry to improve the representation of project structure within project valuation models. Previous mining applications of MAP have tended to treat the ore deposit as a homogenous entity as opposed to a heterogenous one in which the deposit can be subdivided into zones differentiated by size, quality and location. This is an inadequate approach for some mining applications because management may implement operating strategies that capitalize on geological structure such as selective zone closure in response to low mineral prices.
\end{abstract}

This paper introduces a project structure model that reflects the heterogenous nature of mineral deposits by representing the project as a real asset portfolio in which each zone represents a portfolio asset. The project is operated in discrete intervals by choosing, at the start of each interval, an operating mode from a set of competing operating modes. Each mode specifies the combinations of zones that will be active and the amount of project capacity that is built, abandoned or temporarily closed. A two-zone mining example is used to demonstrate the proposed model and show how operating strategies that capitalize on geological structure can add value. 


\section{$5^{\text {th }}$ Annual International Conference on Real Options - Theory Meets Practice \\ Los Angeles, California,United States, 13 and 14 July 2001.}

\subsection{Introduction}

Mine investment analysis is a complex exercise because of project uncertainty, such as mineral price and deposit quality, and the physical structure of the mineral deposit. ${ }^{1}$ Mineral deposits often consist of multiple ore zones that are each differentiated by size, quality and location. The presence of multiple deposit zones complicates mine investment analysis because it allows management to consider operating strategies that capitalize on geological structure. So, in addition to traditional forms of overall project flexibility such as full temporary closure, management can also consider strategies such as selective zone closure or delayed development of an individual zone. The valuation exercise is further complicated by management actions that are implemented on a global project scale but have repercussions at the level of zone operations, for example expanding mineral processing capacity can reduce restrictions on the number of zones that can produce simultaneously.

To simplify the valuation exercise, mine analysts often rely on scenario-based techniques. These techniques aggregate the multi-zone nature of a mine into a single development and production strategy that exogenously specifies the timing of revenues, costs, and zone operations. Essentially, these scenariobased techniques achieve simplicity by concealing project details within a single development and production strategy. The cost of this approach is reduced project insight: The benefits of flexibility, the critical mineral prices signaling strategy changes, and the probability of specific project events cannot be determined.

\subsection{An Overview of Development and Production Options at the Triple-Z Gold Mine}

The interaction between operating policy and geological structure can be demonstrated with an overview of the development and production options confronting the management of Triple-Z Mine in 1998. This mine is an open-pit gold mine located in the western United States and its operations were focused on a single open pit of high-quality reserves, called the Main Pit. The current life-of-mine (LOM) plan estimates that the Main Pit ore reserves will be exhausted within five years and the mine will be forced to close. There are two adjacent reserve areas that may allow the mine life to be extended if they are developed. A conceptual schematic of the Triple $\mathrm{Z}$ Mine is provided in Figure 1.

\footnotetext{
1 The valuation model presented here focuses on mine-level investment analysis where a zone within the mineral deposit represents a production unit of a multi-unit project in a general economic setting. Thus, this model could be used in the power industry where a turbine takes the place of a mineral zone in the valuation of a power plant. This model can also be applied at more macro-oriented levels of analysis such as a portfolio of investment opportunities within a geographical region. See Skaf (2000) for a discussion regarding the investment analysis of a portfolio of petroleum properties.
} 


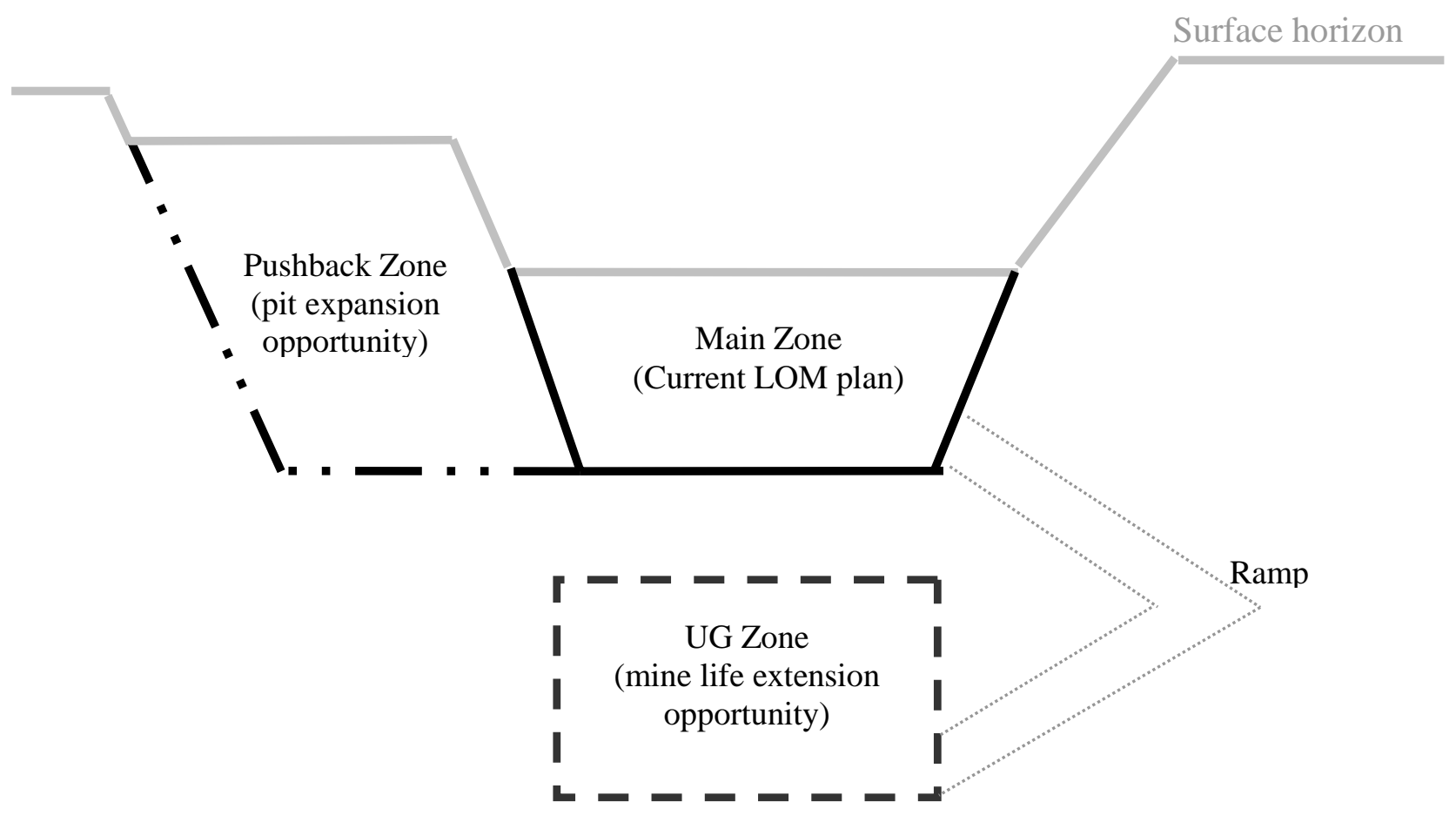

Figure 1. Triple Z Mine schematic layout.

One of these zones is an extension to the Main Pit reserves, called the UG Zone, and its reserves are of higher quality than those contained in the Main Pit (i.e. the amount of gold contained in a ton of ore is greater in the UG Zone). Due to layout of the current pit, the UG Zone can only be exploited by underground mining methods. Development of this zone is expected take 1.5 years and cost $\$ 15.0$ million. In addition, development can only begin once the Main Pit reserves are exhausted since management believes that the best method of accessing the UG Zone is by an access ramp starting at the final Main Zone pit bottom. This zone will provide an additional six years of reserves.

The other zone is a satellite area of low-quality material located adjacent to the Main Pit called the Pushback Zone. Development of the Pushback Zone may start at any quarter-year interval over the operating life of the mine and it will also provide an additional 6 years of reserves. It is expected to cost $\$ 8.0$ million to expose the reserves and take a year to complete. An additional $\$ 10.0$ million will be required to expand mineral processing capacity at the Triple $\mathrm{Z}$ Mine, if the Main Pit or UG Zone is producing when the Pushback Zone is brought into production. 


\section{$5^{\text {th }}$ Annual International Conference on Real Options - Theory Meets Practice \\ Los Angeles, California,United States, 13 and 14 July 2001.}

The additional ore zones provide Triple $\mathrm{Z}$ management with numerous operating options. ${ }^{2}$ Two of these options represent the choice between parallel and sequential investment. The parallel investment strategy is a capacity expansion opportunity whereby the Pushback Zone can be brought into production while operations are continuing in the Main Pit or, once the Main Pit is exhausted, the UG Zone. The sequential investment strategy is a reserve replacement opportunity in which the exhausted Main Pit reserves are replaced by the UG Zone reserves, which in turn are replaced by the Pushback Zone reserves when they are exhausted. Other operating policy issues that management may also consider include but are not limited to:

1) If the Pushback Zone is developed, are there situations when it should be temporarily closed and the mine's fixed costs restructured while one of the higher-quality zones continue in operation?

2) Should development of the Pushback and UG Zones be managed differently? Are there situations in which a sequential investment strategy develops the Pushback Zone before the UG Zone? Are there any environments in which development should be temporarily halted?

3) In what situations should the Triple $\mathrm{Z}$ Mine be abandoned early?

This brief overview of the investment problem confronting management of the Triple-Z Gold Mine illustrates the complexity of mining projects. The existence of multiple ore zones permits operating strategies that cannot be conveniently subsumed into a single development and production scenario or simple decision trees. Management can increase their understanding of alternative development and operating strategies, such as the temporary closure of individual zones, by using a valuation model that provides detailed recognition of geological structure.

\subsection{Previous work}

The modern asset pricing (MAP; more commonly called real options) method has been introduced to the mining industry as an alternative valuation method that is able to handle the dynamic nature of project valuation. However, project structure descriptions within published MAP mining examples typically follow the discounted cash flow (DCF) practice of representing a multiple-zone mining project as a single-zone project via the use of a single development and production strategy, designated in this paper as a Fixed Production Plan (FPP). Such representations allow operational decisions concerning the

${ }^{2}$ A valuation of the Triple- $Z$ Gold Mine was performed by the author that incorporated all of the alterative operating considerations outlined in this section as an exercise to test the project structure model presented in this paper. The name of the mine was changed for reasons of confidentiality. 


\section{$5^{\text {th }}$ Annual International Conference on Real Options - Theory Meets Practice \\ Los Angeles, California,United States, 13 and 14 July 2001.}

project as a whole (e.g. full temporary closure of the project) to be made endogenously but require operational decisions that affect an individual zone (e.g. selective zone development or abandonment) to be specified exogenously as part of the overall life-of-mine plan. The primary drawback of FPP project structure models is their dependence on the mine analyst's ability to aggregate the heterogenous nature of a mineral deposit into a single representative production plan. Such a plan may overlook options created by the geological structure of the project.

The earliest published MAP mine valuation model is the temporary closure model by Brennan and Schwartz (1985). Their model incorporates a FPP to describe operations when the mine is open and considers management's option to avoid operating losses in low mineral price environments by temporarily closing the whole mine. Other operating strategies to avoid operating losses, such as closing select high-cost work areas and restructuring fixed costs, are not included. Palm, Pearson and Read (1986) use the Brennan and Schwartz model to demonstrate that the value of the temporary closure option is dependent upon the proportion of fixed costs to total costs. They showed that the value of temporary closure decreases as the proportion of fixed costs increase because the reduction in operating losses achieved with temporary closure is smaller when fixed costs are high.

Decision-tree methods have been used to describe some of the design complexity confronting the mine planner. ${ }^{3}$ Trigeorgis (1990) presents a decision-tree model for a mining project in which the present value of the remaining cash flows is uncertain. The project incorporates a continuous option to abandon early, an option to defer development for two years, and a European option to expand mine production by $50 \%$ after an initial development and early-production period of six years. Once the project is developed, the expansion option creates two branches in the project decision-tree in which each branch has an associated FPP to describe production. One branch delineates operating policy strategy if no expansion occurs and the other represents the operating policy if expansion does occur. Samis and Poulin $(1996,1998)$ provide a related decision-tree model where mineral price is the underlying source of uncertainty. In their model, management has the option to develop a large low-quality mineralized zone when a smaller high-quality zone, where operations are currently focused, is exhausted in nine years' time.

3 Published examples of decision-tree models used to value petroleum projects include Smit (1997), Chorn and Carr (1997), Laine (1997), and Smith and McCardle (1999). 


\section{$5^{\text {th }}$ Annual International Conference on Real Options - Theory Meets Practice \\ Los Angeles, California,United States, 13 and 14 July 2001.}

In both these models, each branch of the decision tree represents an operating scenario that reflects the management's development strategy, choice of producing zones, and choice of project capacity. The dynamic nature of multi-zone project operation is reflected through the decision tree, which specifies the scenario interactions. Unfortunately, the decision-tree approach has the disadvantage of growing quickly with the number of operational possibilities such that it soon becomes unmanageable.

There are published mine valuation models that allow production policy to be set endogenously without the aid of decision trees. The cut-off grade models ${ }^{4}$ of Mardones (1991, 1993) and Sagi (1998) allow management to control the rate at which the deposit is depleted in response to price fluctuations. Subject to restrictions on mining and mineral processing capacity, management can maximize project value by continually resetting the proportion of mined material that is processed and the proportion that is discarded. Mine life is shortened, when mining capacity is high relative to processing capacity, with a high cut-off grade policy because a larger proportion of the deposit must be mined to produce the same amount of material for processing than under a low cut-off grade policy.

Cortazar and Casassus (2000) provide another model in which production policy is set endogenously. Their model divides the project into production units based on the stage of mineral processing. They demonstrate their model with a mining project that has two stages of mineral processing: removing the ore from the ground (mining) and converting the ore into mineral concentrate (mineral processing). Operational dependence between the project stages is minimized because their model allows management to create a buffer of stockpiled ore between stages. Thus, the mineral processing stage can be closed while mining operations continue and mineral processing operations can be open while mining operations are closed and an ore stockpile exits.

General economic literature contains MAP applications that are a starting point for developing an extended project structure model for mining projects. He and Pindyck (1992) develop a MAP model in which management must chose between investing in product-specific technology and technology that is capable of producing multiple products. Managers of mining projects confront a similar and more

\footnotetext{
${ }^{4}$ In mining literature, the mineral distribution within the deposit is described by a grade-distribution curve. Much like a probability distribution, this curve delineates the proportion of mineralized material that is below a particular quality. The cut-off grade refers to the concentration of mineral (grade) at which mineralized material with a mineral concentration less than this level is discarded as waste and material with a mineral concentration greater than this level is processed as ore.
} 


\section{$5^{\text {th }}$ Annual International Conference on Real Options - Theory Meets Practice \\ Los Angeles, California,United States, 13 and 14 July 2001.}

complicated investment decision since mine investment decisions often requires the choice between capital combinations that consist of product-specific and multi-product components. ${ }^{5}$ For example, product-specific capital investment is required to develop each zone of a mineral deposit and multiproduct capital investment is required to develop facilities for processing ore from all zones (e.g. mineral processing facilities). Thus, the choice of mine capacity includes both selecting the amount of productspecific capital to invest (i.e. the number of zones to develop) and the amount of multi-product capital to invest (i.e. the mineral processing capacity to install) that maximizes value.

Childs (1995) and Childs, Ott and Triantis (1998) propose a model that allows managers to devise a value-maximizing investment policy for a multi-project portfolio. Their model allows management to choose between sequential and parallel investment strategies when there are interrelationships between projects. Mining projects display similar characteristics in that managers must often choose between sequential and parallel investment strategies for the mine's individual zones. However, the multi-project portfolio model of Childs et al must be extended before it can be used to value mining projects because their model details only the development periods of the projects (zones) and not the project operational phases within the project portfolio.

A project structure model is required that can more fully represent the influence of geological structure in a mine valuation exercise. Such a model must recognize the multi-zonal nature of a mining project, allow capital to be directed within expenditure programs to either zone-specific or project-wide applications, and recognize both the development and operational phases of zone exploitation. The model presented in the next section meets these requirements.

\subsection{Model description}

The fleXible Discrete Mine Production (XDMP) model extends the ability of the mine analyst to describe geological structure and the ability to capitalize on it within his or her valuation model. The XDMP model recognizes the mining project as a heterogeneous mineral deposit incorporating multiple ore reserve zones indexed by a set of integers $n=1, \ldots, N$. Each zone is differentiated by the quantity of reserves it contains, the quality (i.e. grade or mineral concentration) of the zone reserves, an exogenous exploitation plan specified by the mine planner (a zone FPP), and the capacity required to process the zone's ore and waste production.

\footnotetext{
${ }^{5} \mathrm{He}$ and Pindyck recognize this aspect of real asset investment in the conclusion of their article.
} 


\section{$5^{\text {th }}$ Annual International Conference on Real Options - Theory Meets Practice \\ Los Angeles, California,United States, 13 and 14 July 2001.}

Management operates the project by committing to the development and production requirements of each active zone and the temporary closure costs associated with inactive zones over a fixed management interval of magnitude, $\mathrm{T}_{\mathrm{M}}$, (e.g. half-year). ${ }^{6}$ At the beginning of each interval, management is confronted with a set of operating modes that define the project's level of production, capacity requirements, and any capacity changes during the next management interval. From one interval to the next, change in production level occurs through zone closure, re-opening of closed zones or developing and operating a new zone. Such changes are achieved by modifying the combination of active zones. Capacity change occurs by building additional capacity, abandoning a portion of existing capacity, or adjusting the level of closed capacity by either closing a portion of currently open capacity or re-opening a portion of currently closed capacity.

In this paper, it is assumed that project costs are known and the riskless interest rate is also known and constant. Macro-economic uncertainty enters the XDMP model through an uncertain mineral price that follows the Ornstein-Uhlenbeck process (see Jacoby and Laughton (1992) and Laughton and Jacoby (1993) for a discussion of this process):

$\mathrm{dS}=\left[\alpha+\frac{1}{2} \sigma^{2}-\gamma \ln \left(\frac{\mathrm{S}}{\mathrm{S}^{*}}\right)\right] \mathrm{Sdt}+\sigma \mathrm{Sdz}$

where: $\mathrm{S}=$ current mineral spot price.

$\mathrm{S}^{*}=$ current long-term price median.

$\alpha=$ short-term growth rate of the price medians.

$\sigma=$ short-term price volatility.

$\gamma=$ rate of reversion.

$\mathrm{dz}=\mathrm{a}$ standard Gauss-Weiner process increment.

This process is derived from a price model in which changes to each future price expectation are proportional to the current price expectation and a random standard normal variable that reflects the

${ }^{6}$ An active zone is defined as one in which development or production operations occur during the next management interval. An inactive zone is defined as one in which no such activities occur. Inactive zones may incur temporary closure costs associated with maintaining the zone in a state such that production activities may resume. 


\section{$5^{\text {th }}$ Annual International Conference on Real Options - Theory Meets Practice \\ Los Angeles, California,United States, 13 and 14 July 2001.}

arrival of new information. The model allows new information to have a declining influence over the term structure of price expectations such that the mineral price can revert to a long-term equilibrium path.

There are four other components to the XDMP model. These are:

1) The zone FPPs used to describe development and production operations in their respective zones.

2) A project state space that describes the development and operating state of each zone and the project's ability to extract and process mineralized material.

3) A set of operating modes representing possible operating policies during a management interval.

4) The methodology used to construct a project decision tree and calculate project value.

\subsection{Zone development and production plan}

For each zone, the mine analyst specifies an exogenous operating policy that defines the zone's development and extraction operations. This policy, called a zone FPP, $\mathrm{Z}_{\mathrm{n}}$, is a sequence of $R_{+}{ }^{5}$ vectors:

$\mathrm{Z}_{\mathrm{n}}=\left\{z_{\mathrm{n}, \mathrm{e}}: \mathrm{e}=0,1, \ldots, \mathrm{E}_{\mathrm{n}} ; z_{\mathrm{n}, \mathrm{e}}=\left(\mathrm{q}_{\mathrm{n}, \mathrm{e}}, \mathrm{g}_{\mathrm{n}, \mathrm{e}}, \mathrm{v}_{\mathrm{n}, \mathrm{e}}, \mathrm{d}_{\mathrm{n}, \mathrm{e}}, \mathrm{u}_{\mathrm{n}, \mathrm{e}}\right) ; \mathrm{q}_{\mathrm{n}, \mathrm{e}}, \mathrm{g}_{\mathrm{n}, \mathrm{e}}, \mathrm{v}_{\mathrm{n}, \mathrm{e}}, \mathrm{d}_{\mathrm{n}, \mathrm{e}}, \mathrm{u}_{\mathrm{n}, \mathrm{e}} \in R_{+}\right\}$

where the index e indicates the combined development and production stage of the zone. Each sequence member, $z_{\mathrm{n}, \mathrm{e}}$, is an information set detailing zone operation parameters. Mineral extraction operations are described by the mining rate, $\mathrm{q}_{\mathrm{n}, \mathrm{e}}$, the grade (mineral concentration) of the current reserves, $\mathrm{g}_{\mathrm{n}, \mathrm{e}}$, and a variable operating cost, $\mathrm{v}_{\mathrm{n}, \mathrm{e}}$. Zone development is parameterized by the capital expenditure incurred, $\mathrm{d}_{\mathrm{n}, \mathrm{e}}$, to prepare the zone for mining operations. An example of such costs would be those associated with prestripping a new pit but not those required to expand project infrastructure to handle additional production from the new pit. ${ }^{7}$ The term, $\mathrm{u}_{\mathrm{n}, \mathrm{e}}$, represents the cost of having the zone $\mathrm{n}$ inactive at extraction index e.

The zone FPP incorporates two assumptions. First, the variable production cost of each zone is assumed to be concave or constant. This assumption ensures that the zone is either operating at full capacity or it is not producing. ${ }^{8}$ Second, the cut-off grade for each zone is set exogenously.

7 The cost of expanding the project's infrastructure is specified within a capacity change model developed by the mine planner. Activities associated with capacity change include purchasing additional rolling stock to handle increased ore and waste production or expanding mineral processing facilities.

${ }^{8}$ If variable production costs are strongly convex, then there may be a benefit to varying the production mix from the various project zones in response to changes in the mineral price. 


\section{$5^{\text {th }}$ Annual International Conference on Real Options - Theory Meets Practice \\ Los Angeles, California,United States, 13 and 14 July 2001.}

The zone FPP can often be divided into two distinct segments. The first segment is a development period and represents preparation for production activities. During this period, $\mathrm{q}_{\mathrm{n}, \mathrm{e}}, \mathrm{g}_{\mathrm{n}, \mathrm{e}}$, and $\mathrm{v}_{\mathrm{n}, \mathrm{e}}$ are likely to be zero and the zone is assumed to have no impact on the project's overall capacity infrastructure. ${ }^{9}$ The second segment represents the production period $\left(\mathrm{q}_{\mathrm{n}, \mathrm{e}}, \mathrm{g}_{\mathrm{n}, \mathrm{e}}, \mathrm{v}_{\mathrm{n}, \mathrm{e}}>0\right)$. The boundary between these two regions defines the point in the zone FPP where a portion of the project's capacity infrastructure must be available to the zone in order for production activities to continue. This boundary is defined as $\mathrm{e}_{\mathrm{CapBdy}} \mathrm{n}$ and the amount of capacity infrastructure required to handle the zone mine and mill production is $\mathrm{w}_{\text {OCap, } \mathrm{n}, \text { mine }}$ and $\mathrm{w}_{\text {OCap, } \mathrm{n}, \text { mill }}$ respectively. ${ }^{10}$

\subsection{Project state space}

The project state space comprises two subspaces or regions in which the first is the deposit subspace:

$$
\mathbf{M}^{\mathbf{r}}=\left\{\mathrm{m}: \mathrm{m}=\left(\mathrm{e}_{1}, \ldots, \mathrm{e}_{\mathrm{N}}\right) ; \mathrm{e}_{\mathrm{n}} \in\left\{0, \ldots, \mathrm{E}_{\mathrm{n}}\right\}\right\}
$$

whose elements, $\mathrm{m}=\left(\mathrm{e}_{1}, \ldots, \mathrm{e}_{\mathrm{N}}\right)$, are an ordered collection of indices $\mathrm{e}_{\mathrm{n}}$ that correspond to the FPP extraction index of zone $\mathrm{n}$. Each element represents a deposit state that defines the development and extraction stage of each zone within the deposit.

The number of states within the deposit subspace can quickly become immense even for a deposit with a modest number of long-lived ore zones. The mine analyst can reduce the number of the states by identifying regions in this subspace that are infeasible from a mine design perspective and then imposing the appropriate constraints. An example of such a constraint is the inability to develop a zone until other zones have reached a particular stage of development and extraction. Access tunnels at an underground mine are often protected from geological instability by limiting the mining activities in a zone surrounding the tunnels. ${ }^{11}$ The reserves contained in this zone only become available for mining when the

9 Obviously, this can be changed if development activities do have an impact on project capacity infrastructure such as the situation when a new zone is being developed underground and all ore and waste must be removed through a single shaft system. It is assumed in this paper that the impact of development activities is subsumed into the cost of zone development. An example of this would be the development of a new open pit zone by independent contractors.

${ }^{10}$ A series of $\mathrm{e}_{\mathrm{CapBdy}, \mathrm{n}}$ can be used to mark changes in capacity requirements if the zone's development period has an impact on project capacity.

${ }^{11}$ Deep underground gold mines in South Africa protect their shafts by curtailing mining activities within a kilometer of the shaft. Mining activities close to the shaft only begin when the outlying areas are mostly exhausted. 


\section{$5^{\text {th }}$ Annual International Conference on Real Options - Theory Meets Practice \\ Los Angeles, California,United States, 13 and 14 July 2001.}

outlying zones that use the access tunnels are depleted or the reserves in the outlying zones are abandoned. The " $r$ " superscript is used to indicate that the mine analyst has imposed constraints on the deposit subspace $\mathbf{M}^{\mathbf{r}}$ (this superscript is also used in defining the capacity subspace and project state space).

The capacity subspace is the second region of the project state space. This region delineates three types of capacity designated open, closed and unfinished. Open capacity defines to the project's current ability to process ore and waste production. Closed capacity indicates the amount of capacity that is temporarily closed but which may be re-opened. Unfinished capacity refers to the progress of various capacity expansion programs (i.e. the current state of "capacity-under-construction") that provide open capacity when completed.

Open project capacity is categorized as either open mine capacity, $\mathrm{w}_{\text {mine, }}$, which reflects the ability to remove in-situ ore and waste, or open mill capacity, $\mathrm{w}_{\text {mill }}$, which reflects the ability to process ore from mining operations. The project's current open capacity is described by the state, $\mathrm{c}_{\text {OCap }}=\left(\mathrm{w}_{\text {mine }}, \mathrm{w}_{\text {mill }}\right)$, where $\mathrm{w}_{\text {mine }}, \mathrm{w}_{\text {mill }} \geq 0$. The set of possible open capacity states, $\mathbf{C}_{\mathbf{O C a p}}$, is discrete and its members, $\mathrm{c}_{\mathrm{OCap}}$, are predetermined by cost efficiency and operational constraints. In particular, membership is limited by the requirement that each open capacity state must match the open capacity requirements of one of the active zone combinations. Open capacity states that do not adhere to this condition are assumed to be cost inefficient because the benefits of excess capacity are assumed not to warrant the additional costs incurred by maintaining excess open capacity. ${ }^{12}$

Closed capacity specifies the amount of capacity that has been temporarily closed so that the costs related to capacity under-utilization are not incurred. The amounts of closed mine capacity, $\mathrm{y}_{\text {mine, }}$, and closed mill capacity, $\mathrm{y}_{\text {mill }}$, is described by the state, $\mathrm{c}_{\mathrm{CCap}}=\left(\mathrm{y}_{\text {mine }}, \mathrm{y}_{\text {mill }}\right)$, where $\mathrm{y}_{\text {mine }}, \mathrm{y}_{\text {mill }} \geq 0$. The set of possible closed capacity states, $\mathbf{C}_{\mathbf{C C a p}}$, is discrete and its members are restricted to states with amounts equal to the differences between the amounts of open capacity that the various active zone combinations require to

\footnotetext{
${ }^{12}$ Capacity under-utilization costs are generated because it is assumed that unused open capacity is maintained in such a state that it can be used at any point during a management interval. An example would be the expense of maintaining excess rolling stock (i.e. trucks or underground ore trains) in a condition that allows it to be swapped for stock currently in use. This restriction does not prevent management from maintaining capacity requirements for two zones when only one is producing. It is meant to reflect an assumed management preference for open capacity states that are equal to the production requirements of an existing active zone combination. For example, an open capacity state set for a two-zone mine may include capacity requirements for one and two zones but not 1.5 zones.
} 


\section{$5^{\text {th }}$ Annual International Conference on Real Options - Theory Meets Practice \\ Los Angeles, California,United States, 13 and 14 July 2001.}

process ore production. For example, a two-zone mine, where one zone required milling capacity of 1000 tonnes / day and the other 1500 tonnes / day, could have closed mill capacity of zero, 1000 or 1500 tonnes / day when the total installed mill capacity is 2500 tonnes / day. Other levels of closed capacity are assumed to be cost inefficient because they incur excess open capacity and maintenance costs.

The XDMP model allows management to increase mill and mine capacity through capacity construction programs. The mine analyst can exogenously specify one or more programs that are indexed by a set of integers, $\mathrm{u}=1, \ldots, \mathrm{U}$, and differentiated by the project capacity required to start the program, the program's duration, the cost of advancing to the next stage of construction and the amount of mining (milling) capacity created by the completed program. Each program contains multiple construction stages that are of constant duration, $\mathrm{T}_{\mathrm{M}}$, and indexed by integers, $\mathrm{BI}_{\mathrm{u}}=0,1, \ldots, \mathrm{BI}_{\mathrm{u} \text {, Final }}$. A construction program provides additional mine capacity, $\mathrm{MineC}_{\mathrm{u}}$, and mill capacity, $\mathrm{MillC}_{\mathrm{u}}$, when completed, where MineC $_{u}$, MillC $_{u} \geq 0$.

Progress through the various capacity expansion programs is described by an unfinished capacity state, $\mathrm{c}_{\mathrm{UCap}}=\left(\mathrm{BI}_{1}, \ldots, \mathrm{BI}_{\mathrm{U}}\right)$. The set of unfinished capacity states, $\mathbf{C}_{\mathbf{U C a p}}$, is discrete and its members are limited by the assumption that only one capacity expansion program can be partially completed or in progress at any given time. Thus, when the $\mathrm{u}^{\prime}$ expansion program is in progress, the build indices of unfinished capacity state, $\mathrm{c}_{\mathrm{UCap}}=\left(\mathrm{BI}_{1}, \ldots, \mathrm{BI}_{\mathrm{U}}\right)$, are:

$\mathrm{BI}_{\mathrm{u}}= \begin{cases}0<\mathrm{BI}_{\mathrm{u}}<\mathrm{BI}_{\mathrm{u}, \text { Final }} & \mathrm{u}=\mathrm{u}^{\prime} \\ 0 \text { or } \mathrm{BI}_{\mathrm{u}, \text { Final }} & \mathrm{u} \neq \mathrm{u}^{\prime}\end{cases}$

The three capacity sets, $\mathbf{C}_{\mathbf{O C a p}}, \mathbf{C}_{\mathbf{C C a p}}$, and, $\mathbf{C}_{\text {Ucap }}$, can be combined to create a capacity subspace, $\mathbf{C}^{\mathbf{r}}$. Members take the form, $\mathrm{c}=\left(\mathrm{w}_{\text {mine }}, \mathrm{w}_{\text {mill }}, \mathrm{y}_{\text {mine }}, \mathrm{y}_{\text {mill }}, \mathrm{BI}_{1}, \ldots, \mathrm{BI}_{\mathrm{U}}\right)$, and they describe the project's ability to process production, the amount of capacity that is temporarily closed, and the extent of the expansion programs. The capacity subspace is not equal to $\mathbf{C}_{\mathbf{O C a p}} \times \mathbf{C}_{\mathbf{C C a p}} \times \mathbf{C}_{\mathbf{U C a p}}$ because many combinations are infeasible. For example, no further expansion programs are justified once maximum capacity levels have been reached and capacity states, $\mathrm{c}=\left(\mathrm{w}_{\text {Max mine }}, \mathrm{w}_{\text {Max mill }}, 0,0, \mathrm{BI}_{1}, \ldots, \mathrm{BI}_{\mathrm{U}}\right)$, where $\mathrm{BI}_{\mathrm{u}} \neq 0, \mathrm{BI}_{\mathrm{u} \text {, Final }}$ is infeasible. In addition, to further compress the capacity subspace, it is assumed that unfinished capacity 


\section{$5^{\text {th }}$ Annual International Conference on Real Options - Theory Meets Practice \\ Los Angeles, California,United States, 13 and 14 July 2001.}

is immediately abandoned or converted to either open (at no cost) or closed capacity (at some cost) ${ }^{13}$ upon completion of an expansion program.

The project state space, $\mathbf{P}^{\mathbf{r}}$, is the result of combining the deposit space, $\mathbf{M}^{\mathbf{r}}$, and the capacity space, $\mathbf{C}^{\mathbf{r}}$. This state space is defined:

$\mathbf{P}^{\mathrm{r}}=\left\{\mathrm{p}: \mathrm{p}=(\mathrm{m}, \mathrm{c}) ; \mathrm{m} \in \mathbf{M}^{\mathrm{r}}, \mathrm{c} \in \mathbf{C}^{\mathrm{r}}\right\}$

\subsection{A set of operating modes}

A set of operating modes, $\Upsilon$, specifies the possible methods that management may use to operate the project. At any particular starting project state, $\mathrm{p}=(\mathrm{m}, \mathrm{c})$, the actual set of operating modes, $\Upsilon_{\mathrm{p}}=\left\{v_{\mathrm{a}} ; \mathrm{a}=1, \ldots, \mathrm{A}\right\}$, available to management may be constrained such that $\Upsilon_{\mathrm{p}} \subseteq \Upsilon$. Over a management interval, management operates the project from state " $p$ " to an ending state, $p^{\prime}=\left(m^{\prime}, c^{\prime}\right)$, by selecting an operating mode, $v_{\mathrm{a}}$. This mode is defined as the difference between two project states:

$$
\begin{aligned}
v_{\mathrm{a}} & =\mathrm{p}^{\prime}-\mathrm{p} \\
& =\left(\Delta \mathrm{e}_{1}, \ldots, \Delta \mathrm{e}_{\mathrm{N}}, \Delta \mathrm{w}_{\text {mine }}, \Delta \mathrm{w}_{\text {mill }}, \Delta \mathrm{y}_{\text {mine }}, \Delta \mathrm{y}_{\text {mill }}, \Delta \mathrm{BI}_{1}, \ldots, \Delta \mathrm{BI}_{\mathrm{U}}\right)
\end{aligned}
$$

The first $\mathrm{N}$ elements, $\Delta \mathrm{e}_{\mathrm{n}}=\mathrm{e}_{\mathrm{n}}^{\prime}-\mathrm{e}_{\mathrm{n}}$, indicate development and production activity in zone $\mathrm{n}$. They assume a value of one if the zone is active and zero if the zone is inactive or temporarily closed. The remaining elements represent changes in capacity state. The magnitude of open mine (mill) capacity change is defined by $\Delta \mathrm{w}_{\text {mine (mill) }}=\mathrm{w}_{\text {mine (mill) }}^{\prime}-\mathrm{w}_{\text {mine (mill) }}$ and the magnitude of closed mine (mill) capacity change by $\Delta \mathrm{y}_{\text {mine (mill) }}=\mathrm{y}_{\text {mine (mill) }}^{\prime}-\mathrm{y}_{\text {mine (mill) }}$. The final elements, $\Delta \mathrm{BI}_{\mathrm{u}}=\mathrm{BI}_{\mathrm{u}}^{\prime}-\mathrm{BI}_{\mathrm{u}}$, indicate which expansion program is in progress. $\Delta \mathrm{BI}_{\mathrm{u}}$ is equal to one if expansion program $\mathrm{u}$ is active during the next management period and zero if the program is not.

Operating modes may include both instantaneous changes in project state and changes that occur over a management interval. In this paper, immediate changes in project state are produced by re-opening closed capacity, closing open capacity or abandoning part of the installed capacity base so that: ${ }^{14}$

\footnotetext{
${ }^{13}$ The capacity produced from a completed expansion program may be temporarily closed instead of being brought into production. The cost associated with this action is assumed to be equal to the cost of closing an equivalent amount of open capacity (see equation 11). Temporarily closing recently completed capacity allows management to avoid the costs associated with hiring new employees to operate the new capacity infrastructure.
} 


$$
\begin{aligned}
& \Delta \mathrm{w}_{\text {mine }}=-\left(\Delta \mathrm{y}_{\text {mine }}+\mathrm{y}_{\mathrm{ABD}, \text { mine }}+\mathrm{w}_{\mathrm{ABD} \text {, mine }}\right) \\
& \Delta \mathrm{w}_{\text {mill }}=-\left(\Delta \mathrm{y}_{\text {mill }}+\mathrm{y}_{\mathrm{ABD} \text {, mill }}+\mathrm{w}_{\mathrm{ABD}, \text { mill }}\right)
\end{aligned}
$$

where:

$\mathrm{y}_{\mathrm{ABD} \text {, mine }}, \mathrm{y}_{\mathrm{ABD} \text {, mill }}=$ the amount of closed mine and mill capacity abandoned.

$\mathrm{w}_{\mathrm{ABD} \text {, mine }}, \mathrm{w}_{\mathrm{ABD} \text {, mill }}=$ the amount of open mine and mill capacity abandoned.

Operating mode activities that require a management interval to complete include finishing a stage of a capacity expansion program, zone development and mineral production. When a capacity expansion program is finished, the additional capacity provided by the program is added immediately to the project's stock of either open or closed capacity so that $\Delta \mathrm{w}_{\text {mine }}=\operatorname{MineC}_{\mathrm{u}}$ and $\Delta \mathrm{w}_{\text {mill }}=\operatorname{MillC}_{\mathrm{u}}$ or $\Delta \mathrm{y}_{\text {mine }}=\operatorname{MineC}_{\mathrm{u}}$ and $\Delta \mathrm{y}_{\text {mill }}=$ MillC $_{\mathrm{u}}$.

The choice of operating mode can be constrained by the project environment and the amount of open capacity. The project environment is represented by the subspace, $\mathbf{M}^{\mathbf{r}}$, and this subspace incorporates geological structure and mine design considerations. Operating modes are not permissible that lead to ending project states, $\mathrm{p}^{\prime}=\left(\mathrm{m}^{\prime}, \mathrm{c}^{\prime}\right)$, where $\mathrm{m}^{\prime} \notin \mathbf{M}^{\mathbf{r}}$. An example of such a restriction occurs when the reserves of a particular zone are exhausted. In this situation, operating modes that include production from the exhausted zone cannot be considered.

The level of open capacity can also limit the choice of interval operating mode because each mode requires a minimum amount of open capacity to process mineral production. The minimum open capacity requirement is:

$$
\begin{aligned}
\mathrm{w}_{v_{\mathrm{a}}, \text { mine }} & =\sum_{\mathrm{n}=1}^{\mathrm{N}}\left\{\begin{array}{ll}
\mathrm{w}_{\text {OCap, } \mathrm{n}, \text { mine }} & \text { when } \mathrm{e}_{\mathrm{n}} \geq \mathrm{e}_{\text {CapBdy, } \mathrm{n}} \\
0 & \text { when } \mathrm{e}_{\mathrm{n}}<\mathrm{e}_{\text {CapBdy }, \mathrm{n}}
\end{array} \text { or zone } \mathrm{n}\right. \text { is inactive. } \\
\mathrm{w}_{v_{\mathrm{a}}, \text { mill }} & =\sum_{\mathrm{n}=1}^{\mathrm{N}}\left\{\begin{array}{ll}
\mathrm{w}_{\text {OCap, } \mathrm{n}, \text { mill }} & \text { when } \mathrm{e}_{\mathrm{n}} \geq \mathrm{e}_{\text {CapBdy, } \mathrm{n}} \\
0 & \text { when } \mathrm{e}_{\mathrm{n}}<\mathrm{e}_{\text {CapBdy }, \mathrm{n}}
\end{array} \text { or zone } \mathrm{n}\right. \text { is inactive. }
\end{aligned}
$$

\footnotetext{
${ }^{14}$ Re-opening closed capacity or closing open capacity could both be modeled with a time lag of one management period if this was considered important.
} 


\section{$5^{\text {th }}$ Annual International Conference on Real Options - Theory Meets Practice \\ Los Angeles, California,United States, 13 and 14 July 2001.}

An operating mode, $v_{\mathrm{a}}$, cannot be selected for the next management interval at an initial project state "p" if $\mathrm{w}_{v_{\mathrm{p}} \text {, mine }}>\mathrm{w}_{\mathrm{p} \text {, mine }}$ or $\mathrm{w}_{v_{\mathrm{p}}, \text { mill }}>\mathrm{w}_{\mathrm{p} \text {, mill }}$. This restriction can be lifted by converting closed capacity to open capacity when $\mathrm{y}_{\mathrm{p}, \text { mine }} \geq \mathrm{w}_{v_{\mathrm{a}} \text {, mine }}-\mathrm{w}_{\mathrm{p} \text {, mine }}$ and $\mathrm{y}_{\mathrm{p} \text {, mill }} \geq \mathrm{w}_{v_{\mathrm{a}} \text {, mill }}-\mathrm{w}_{\mathrm{p}, \text { mill }}$.

\subsection{Project valuation method}

A project conforming to the description of the previous section can be considered a directed graph ${ }^{15}$ and as such may be valued using a graphing algorithm ${ }^{16}$ and dynamic programming methods. Given an initial project state and set of possible operating modes, the graphing algorithm generates a decision tree that delineates all possible project operation strategies. Project value is calculated by searching the tree for paths to terminal or fully valued project states once the decision tree has been generated. When such a path is found, the project value at the end of the path is used to start a valuation dynamic program. The dynamic program continues working back along the current path of the decision tree until another path to a terminal or a fully valued project state is found. The current project value is determined once all project states in the decision tree have been valued.

At each node within the decision tree, management is confronted with a set of alternative operating modes, one of which must be chosen for the next management interval. The project valuation function, $\mathrm{H}_{\mathrm{t}}\left(\mathrm{S}_{\mathrm{t}} ; \mathrm{p}_{\mathrm{t}}, v_{\mathrm{t}}\right)$, is calculated from the dynamic program:

$\mathrm{H}_{\mathrm{t}}\left(\mathrm{S}_{\mathrm{t}} ; \mathrm{p}_{\mathrm{t}}, v_{\mathrm{t}}\right)=\max _{v_{\mathrm{a}} \in \mathrm{r}_{\mathrm{p}}}\left(\pi\left(\mathrm{p}_{\mathrm{t}}, v_{\mathrm{t}}, v_{\mathrm{a}}\right)+\mathrm{V}\left(\mathrm{S}_{\mathrm{t}}, \tau=\mathrm{T}_{\mathrm{m}} ; \mathrm{p}_{\mathrm{t}}, v_{\mathrm{a}}\right)\right)$

where:

$\pi\left(\mathrm{p}_{\mathrm{t}}, v_{\mathrm{t}}, v_{\mathrm{a}}\right)=-\operatorname{CAPEX}_{\mathrm{m}_{\mathrm{t}}, v_{\mathrm{a}}}-\operatorname{CapChge}_{\mathrm{c}_{\mathrm{t}}, v_{\mathrm{a}}}-\operatorname{ProdChge}\left(\mathrm{p}_{\mathrm{t}}, v_{\mathrm{t}}, v_{\mathrm{a}}\right)-$ T.C. $\left(v_{\mathrm{t}}, v_{\mathrm{a}}\right)$

Zone capital expenditure, CAPEX $\mathrm{m}_{\mathrm{t}}, v_{\mathrm{a}}$, is incurred from active zone development at project state, $\mathrm{p}_{\mathrm{t}}$, and in operating mode, $v_{\mathrm{a}}$. Active zone development costs are the sum of the development costs specified in the active zone FPP:

\footnotetext{
${ }^{15}$ A graph is a pair of sets in which the first set consists of a finite number of elements and the second set comprises binary relationships linking the elements of the first set. The multi-zone mine may be represented as a graph because the project state space, $\mathrm{P}^{\mathrm{r}}$, forms the first set and the operating modes delineate the binary relationships between the project states. The project is a directed graph because the project states are ordered since zone reserves cannot be replaced once mined. See Chapter 5 - Section 4 of Cormen, Leiserson and Rivest (1997) for a detailed discussion of directed graphs.

${ }^{16}$ Graphing algorithms are discussed in Chapter 23 of Cormen, Leiserson and Rivest (1997).
} 
$\operatorname{CAPEX}_{\mathrm{m}_{\mathrm{t}}, v_{\mathrm{a}}}=\sum_{\mathrm{n}=1}^{\mathrm{N}} \begin{cases}\mathrm{d}_{\mathrm{n}, \mathrm{e}} & \text { when } \Delta \mathrm{e}_{\mathrm{n}}=1 . \\ 0 & \text { when } \Delta \mathrm{e}_{\mathrm{n}}=0 .\end{cases}$

Capacity change costs, CapChge $\mathrm{c}_{\mathrm{c}_{\mathrm{t}}, v_{\mathrm{a}}}$, are produced from one of the four types of capacity change such that: ${ }^{17}$

CapChge $_{\mathrm{c}_{\mathrm{t}}, v_{\mathrm{a}}}=\left\{\begin{array}{l}f_{\mathrm{BUILD}}\left(\mathrm{c}, \Delta \mathrm{BI}_{1}, \ldots, \Delta \mathrm{BI}_{\mathrm{U}}\right) \\ f_{\text {CLOSE }}\left(\mathrm{c}, \Delta \mathrm{w}_{\text {mine }}, \Delta \mathrm{w}_{\text {mill }}\right) \\ f_{\text {REOPEN }}\left(\mathrm{c}, \Delta \mathrm{y}_{\text {mine }}, \Delta \mathrm{y}_{\text {mill }}\right) \\ f_{\mathrm{ABD}}\left(\mathrm{c}, \Delta \mathrm{w}_{\text {mine }}, \Delta \mathrm{w}_{\text {mill }}, \Delta \mathrm{y}_{\text {mine }}, \Delta \mathrm{y}_{\text {mill }}\right)\end{array}\right.$

where:

$f_{\text {BUILD }}(\cdot)=$ the cost of building another stage of a capacity expansion program.

$f_{\text {CLOSE }}(\cdot)=$ the cost of temporarily closing open capacity.

$f_{\text {REOPEN }}(\cdot)=$ the cost of re-opening closed capacity.

$f_{\mathrm{ABD}}(\cdot)=$ the cost of abandoning open, closed and unfinished capacity.

Production change costs, ProdChge $\left(\mathrm{p}_{\mathrm{t}}, v_{\mathrm{t}}, v_{\mathrm{a}}\right)$, are incurred when switching between the current operating mode and an alternative operating mode causes mill and mine production to fluctuate. This cost reflects retrenchment or hiring costs associated with large changes in production levels. Implicit in this term is the assumption that the mine does not retain any unnecessary production personnel.

The final term, T.C. $\left(v_{\mathrm{t}}, v_{\mathrm{a}}\right)$, represents miscellaneous costs incurred when changing the active zone combination. For example, such costs are incurred when removing equipment (e.g. winches or pumps) from zones that have been exhausted or temporarily closed. These cost are assumed to be dependent only on the change in operating mode. They can be made dependent on the deposit subspace if required. ${ }^{18}$

${ }^{17}$ Mining literature provides guidelines for cost functions related to building new capacity such as the 6/10ths rule where the cost of adding unit capacity decreases with the amount of capacity being built. This rule and other capacity cost curves are discussed in O'Hara (1980) and Mular and Poulin (1998). In this paper, the cost of building additional capacity follows this convention when there is a pre-existing base of installed capacity. There appear to be only anecdotal data in the literature for the other types of capacity change.

${ }^{18}$ For example, it could be less costly to change into an operating mode when some of the active zones are still being developed than when all the active zones are producing mineral. 


\section{$5^{\text {th }}$ Annual International Conference on Real Options - Theory Meets Practice \\ Los Angeles, California,United States, 13 and 14 July 2001.}

The term, $\mathrm{V}\left(\mathrm{S}_{\mathrm{t}}, \tau=\mathrm{T}_{\mathrm{m}} ; \mathrm{p}_{\mathrm{t}}, v_{\mathrm{a}}\right)$, represents the project value in operating mode, $v_{\mathrm{a}}$, at state, $\mathrm{p}_{\mathrm{t}}$, immediately after the costs of zone development, capacity change, production change and operating mode transition have been incurred. Investors are assumed to be able to hedge mineral price uncertainty in the financial markets so that arbitrage valuation arguments can be used to derive the following partial differential equation governing project value: ${ }^{19}$

$\frac{1}{2} \sigma^{2} \mathrm{~S}^{2} \mathrm{~V}_{\mathrm{SS}}+(\mathrm{r}-\mathrm{c}) \mathrm{SV} \mathrm{V}_{\mathrm{S}}-\mathrm{V}_{\tau}-\mathrm{rV}=0$

where:

$\mathrm{S}=\quad=$ the current mineral spot price.

$\sigma \quad=$ the short term standard deviation of the mineral spot price.

c $\quad=$ a convenience yield.

$=\mathrm{r}+\mathrm{PRisk}_{\text {Mineral }} \cdot \sigma-\alpha-\frac{1}{2} \sigma^{2}+\gamma \cdot \ln \left(\frac{\mathrm{S}}{\mathrm{S}^{*}}\right)$

$\mathrm{r} \quad=$ the riskless interest rate.

PRisk $_{\text {Mineral }}=$ the price of market risk $\times$ correlation between market and mineral price uncertainty.

$\tau=$ a continuous time variable over the interval $0 \leq \tau \leq \mathrm{T}_{\mathrm{m}}$.

The valuation partial differential equation is subject to several boundary conditions. The terminal boundary condition is:

$\mathrm{V}\left(\mathrm{S}, \tau=0 ; \mathrm{p}_{\mathrm{t}}, v_{\mathrm{a}}\right)=$ C.F. $(\mathrm{S})_{\mathrm{p}_{\mathrm{t}}, v_{\mathrm{a}}}+\mathrm{H}_{\mathrm{t}+1}\left(\mathrm{~S} ; \mathrm{p}_{\mathrm{t}+1}^{\prime}, v_{\mathrm{t}+1}=v_{\mathrm{a}}\right)$

where:

C.F. $(\mathrm{S})_{\mathrm{p}_{\mathrm{t}}, v_{\mathrm{a}}} \quad$ = discrete cash flow generated by mineral production; defined in equation 18.

$\mathrm{H}_{\mathrm{t}+1}\left(\mathrm{~S} ; \mathrm{p}_{\mathrm{t}+1}^{\prime}, v_{\mathrm{t}+1}=v_{\mathrm{a}}\right)=$ project value after one management interval in operating mode $v_{\mathrm{a}}$ at the ending project state $\mathrm{p}_{\mathrm{t}+1}^{\prime}$.

$\mathrm{p}_{\mathrm{t}+1}^{\prime} \quad=$ ending project state at which an expansion program may be completed.

Discrete cash flows, C.F.(S), are incorporated into the terminal boundary condition to conform to the observation that production activity must occur before a (possibly unprofitable) cash flow can be

\footnotetext{
${ }^{19}$ See Brennan and Schwartz (1985) or Dixit and Pindyck (1994) for a derivation of equation (12). The actual form
} of the PDE may change depending on whether project cash flow is generated discretely or continuously. 


\section{$5^{\text {th }}$ Annual International Conference on Real Options - Theory Meets Practice \\ Los Angeles, California,United States, 13 and 14 July 2001.}

generated. The final term, $\mathrm{H}_{\mathrm{t}+1}\left(\mathrm{~S} ; \mathrm{p}_{\mathrm{t}+1}^{\prime}, v_{\mathrm{t}+1}=v_{\mathrm{a}}\right)$, represents the project value in the new project state, $\mathrm{p}_{\mathrm{t}+1}^{\prime}$. This term is dependent upon whether a capacity expansion program is completed at the end of the current management interval. If no such program is finished, then the value of project is the value of the project at the new project state, $\mathrm{H}_{\mathrm{t}+1}\left(\mathrm{~S} ; \mathrm{p}_{\mathrm{t}+1}, v_{\mathrm{t}+1}=v_{\mathrm{a}}\right)$. When an expansion program is completed, then management must choose between converting the new project capacity into closed or open capacity depending upon the project's outlook so that:

$$
\begin{aligned}
& \mathrm{H}_{\mathrm{t}+1}\left(\mathrm{~S} ; \mathrm{p}_{\mathrm{t}+1}^{\prime}, v_{\mathrm{t}+1}=v_{\mathrm{a}}\right)= \\
& \quad \max \left(\mathrm{H}_{\mathrm{t}+1}\left(\mathrm{~S} ; \mathrm{p}_{\mathrm{t}+1, \Delta \mathrm{w}}, v_{\mathrm{t}+1}=v_{\mathrm{a}}\right)-\mathrm{UCO}_{\mathrm{c}_{\mathrm{t}}, v_{\mathrm{a}}}, \mathrm{H}_{\mathrm{t}+1}\left(\mathrm{~S} ; \mathrm{p}_{\mathrm{t}+1, \Delta \mathrm{y}}, v_{\mathrm{t}+1}=v_{\mathrm{a}}\right)-\mathrm{UCC}_{\mathrm{c}_{\mathrm{t}}, v_{\mathrm{a}}}\right)
\end{aligned}
$$

where:

$$
\begin{array}{ll}
\mathrm{UCO}_{c_{t}, v_{\mathrm{a}}} & =\text { the cost of converting unfinished capacity into open capacity. } \\
\mathrm{UCC}_{\mathrm{c}_{\mathrm{t}}, v_{\mathrm{a}}} & =\text { the cost of converting unfinished capacity into closed capacity. } \\
\mathrm{p}_{\mathrm{t}+1, \Delta \mathrm{w}} & =\text { ending project state at which unfinished capacity is converted into open capacity. } \\
\mathrm{p}_{\mathrm{t}+1, \Delta \mathrm{y}} & =\text { ending project state at which unfinished capacity is converted into closed capacity. }
\end{array}
$$

By closing the new capacity, management avoid the costs associated with hiring employees to operate the new capacity but incur the cost of placing this capacity into a temporary closure state. By opening the new capacity, the project incurs the cost of making this capacity operational but receives the benefits of expanded capacity.

The project can be abandoned at any time with payment of an abandonment cost, $\mathrm{B}_{\mathrm{ABD}, \mathrm{p}_{\mathrm{t}}}$, that is calculated: ${ }^{20}$

$$
\mathrm{B}_{\mathrm{ABD}, \mathrm{p}_{\mathrm{t}}}=\text { SiteClosure }+\operatorname{CapABD} \mathrm{c}_{\mathrm{t}}+\operatorname{ProdChge}\left(\mathrm{p}_{\mathrm{t}}, v_{\mathrm{a}}, v_{\mathrm{ABD}}\right)+\text { T.C. }\left(v_{\mathrm{a}}, v_{\mathrm{ABD}}\right)
$$

where:

SiteClosure $\quad=$ the cleanup cost incurred on closure.

$\operatorname{CapABD}_{\mathrm{c}_{\mathrm{t}}} \quad=$ the cost of abandoning processing capacity at capacity state $\mathrm{c}_{\mathrm{t}}$.

ProdChge $\left(\mathrm{p}_{\mathrm{t}}, v_{\mathrm{a}}, v_{\mathrm{ABD}}\right)=$ the production change costs incurred during project abandonment.

T.C. $\left(v_{\mathrm{a}}, v_{\mathrm{ABD}}\right) \quad=$ the cost of reducing the number of active zones to zero.

\footnotetext{
${ }^{20}$ The abandonment cost may be zero because of limited liability when the project is the sole asset of the mining company. In this paper, it is assumed that the project is only one of several other mines owned by the company so that avoiding the abandonment costs of this project would place ownership of the other mines in jeopardy. In the case of single-mine companies, environmental regulators can levy a special cash flow charge during operations to ensure that environmental obligations are fulfilled.
} 


\section{$5^{\text {th }}$ Annual International Conference on Real Options - Theory Meets Practice \\ Los Angeles, California,United States, 13 and 14 July 2001.}

Continuous abandonment creates a lower free price boundary that is denoted by a critical abandonment price, $\mathrm{S}_{\mathrm{ABD}}$. The solution of the valuation PDE must meet two conditions at this boundary. First, the operating project's value must be equal to the abandoned project's value. Since cash flows are discrete, the abandonment value is supplemented with the value of production generated between the start of the management interval and the time of abandonment. ${ }^{21}$ This condition is represented at the free boundary as:

$\mathrm{V}\left(\mathrm{S}_{\mathrm{ABD}}, \tau ; \mathrm{p}_{\mathrm{t}}, v_{\mathrm{a}}\right)=-\mathrm{B}_{\mathrm{ABD}, \mathrm{p}_{\mathrm{t}}}+\frac{\left(\mathrm{T}_{\mathrm{m}}-\tau\right)}{\mathrm{T}_{\mathrm{m}}} \cdot \mathrm{C} \cdot \mathrm{F}_{\mathrm{p}_{\mathrm{t}}, v_{\mathrm{a}}} \quad 0 \leq \tau \leq \mathrm{T}_{\mathrm{m}}$

The second condition requires the project value function's to be continuous at the abandonment boundary. ${ }^{22}$ This condition requires:

$\mathrm{V}_{\mathrm{S}}\left(\mathrm{S}_{\mathrm{ABD}}, \tau ; \mathrm{p}_{\mathrm{t}}, v_{\mathrm{a}}\right)=\frac{\left(\mathrm{T}_{\mathrm{m}}-\tau\right)}{\mathrm{T}_{\mathrm{m}}} \cdot \frac{\partial\left(\mathrm{C} . \mathrm{F}_{\mathrm{p}_{\mathrm{t}}, v_{\mathrm{a}}}(\mathrm{S})\right)}{\partial \mathrm{S}} \quad 0 \leq \tau \leq \mathrm{T}_{\mathrm{m}}$

Note that free boundary conditions are not required for the transition between non-abandonment operating modes because these transitions happen on a discrete basis. The discrete nature of non-abandonment decisions also obviates the need to control investment decisions with the free boundary conditions presented in Majd and Pindyck (1987) and Milne and Whalley (2000).

The project cash flow for the next management interval is calculated using the parameters for project state, $\mathrm{p}_{\mathrm{t}}$, and operating mode, $v_{\mathrm{a}}$, with the equation:

${ }^{21}$ This abandonment boundary formulation assumes that production is generated at a constant rate over the management interval. All mineral produced in the current management interval prior to abandonment is sold at the prevailing market price and all costs incurred producing this mineral are due. Note that management would always abandon the project during a management interval when the cash flow term is not part of this boundary condition since negative cash flow outcomes for the current management interval could be avoided.

${ }^{22}$ This condition requires that the price derivative of the value function when the project is equal the value function's price derivative when the project is operating. This condition may be justified using arbitrage arguments (Sick, 1989; Dixit, 1993). 
C.F. $\cdot_{p_{t}, v_{a}}=-$ MCapC $_{\mathrm{c}_{\mathrm{t}}, v_{\mathrm{a}}}-\mathrm{UUCapC}_{\mathrm{p}_{\mathrm{t}}, v_{\mathrm{a}}}+\sum_{\mathrm{n}=1}^{\mathrm{N}} \begin{cases}\left(\mathrm{g}_{\mathrm{n}, \mathrm{m}_{\mathrm{t}}} \mathrm{S}_{\tau}-\eta_{\mathrm{m}_{\mathrm{t}}, v_{\mathrm{a}}} \mathrm{v}_{\mathrm{n}, \mathrm{m}_{\mathrm{t}}}\right) \mathrm{q}_{\mathrm{n}, \mathrm{m}_{\mathrm{t}}} & \text { if } \Delta \mathrm{e}_{\mathrm{n}, v_{\mathrm{a}}}=1 . \\ -\mathrm{u}_{\mathrm{n}, \mathrm{m}_{\mathrm{t}}} & \text { if } \Delta \mathrm{e}_{\mathrm{n}, v_{\mathrm{a}}}=0 .\end{cases}$

where:

MCapC $_{\mathrm{c}_{\mathrm{t}}, v_{\mathrm{a}}}=$ cost of maintaining the same level of capacity at capacity state $\mathrm{c}_{\mathrm{t}}$ and operating mode $v_{\mathrm{a}}$. $\mathrm{UUCapC}_{\mathrm{p}_{\mathrm{t}}, v_{\mathrm{a}}}=$ cost of having under-utilized open capacity at project state $\mathrm{p}_{\mathrm{t}}$ and operating mode $v_{\mathrm{a}}$.

$\Delta \mathrm{e}_{\mathrm{n}} \quad= \begin{cases}1 & \text { if zone } \mathrm{n} \text { is active in operating mode } v_{\mathrm{a}} . \\ 0 & \text { if zone } \mathrm{n} \text { is not active in operating mode } v_{\mathrm{a}} .\end{cases}$

$\mathrm{g}_{\mathrm{n}, \mathrm{m}_{\mathrm{t}}} \quad=$ the grade of zone $\mathrm{n}$ at deposit state $\mathrm{m}_{\mathrm{t}}$.

$\eta_{\mathrm{m}_{\mathrm{t}}, v_{\mathrm{a}}}=$ economy-of-scale benefit associated with deposit state $\mathrm{m}_{\mathrm{t}}$ and operating mode $v_{\mathrm{a}}$.

$\mathrm{v}_{\mathrm{n}, \mathrm{m}_{\mathrm{t}}} \quad=$ the variable cost of zone $\mathrm{n}$ at deposit state $\mathrm{m}_{\mathrm{t}}$.

$\mathrm{q}_{\mathrm{n}, \mathrm{m}_{\mathrm{t}}} \quad=$ the production rate of zone $\mathrm{n}$ at deposit state $\mathrm{m}_{\mathrm{t}}$.

$\mathrm{u}_{\mathrm{n}, \mathrm{m}_{\mathrm{t}}} \quad=$ the cost of maintaining zone $\mathrm{n}$ in a temporarily closed state at deposit state $\mathrm{m}_{\mathrm{t}}$.

The term, $\mathrm{MCapC}_{\mathrm{c}_{\mathrm{t}}, v_{\mathrm{a}}}$, represents the costs generated by having a positive level of closed capacity or by having positive unfinished capacity levels when a capacity construction program has been temporarily halted. Positive levels of closed capacity generate costs from maintaining unused equipment and production facilities, such as a pit crusher and conveyor belt system, in a viable state. The costs associated with temporarily stopping a construction program result from efforts to retain the building site, such as a shaft-deepening project or a mill extension, in a reasonable state. These costs provide management with an incentive, in periods of low mineral prices, to either continue capacity construction once started or to abandon the program. This cost is assumed to have a magnitude of zero whenever there is no closed capacity and either the unfinished capacity balance is zero or a capacity construction program is in progress (i.e. $\Delta \mathrm{BI}_{\mathrm{u}}=1$ ).

The term, $\mathrm{UUCapC}_{\mathrm{p}_{\mathrm{t}}, v_{\mathrm{a}}}$, represents the cost associated with under-utilizing current open capacity and it is dependent upon both the actual amount of open capacity and the active zones of operating mode, $v_{\mathrm{a}}$, that are producing mineral. An example of such a cost would be maintaining a fully staffed shaft complex when mine production only justifies a portion of the personnel. As mentioned in section 2.1, active zones that are being developed do not contribute to production that must be handled by open capacity. 


\section{$5^{\text {th }}$ Annual International Conference on Real Options - Theory Meets Practice \\ Los Angeles, California,United States, 13 and 14 July 2001.}

The term, $\eta_{\mathrm{m}_{\mathrm{t}}, v_{\mathrm{a}}}$, introduces economies of scale to the cash flow equation such that an operating mode with twice the production of an alternative operating mode may have operating costs that are less than twice that of the alternative operating mode. This term is dependent on the deposit state, $\mathrm{m}_{\mathrm{t}}$, because it is assumed that operating economies of scale are only gained from the operation of multiple zones. If any zones of operating mode, $v_{\mathrm{a}}$, are being developed at deposit state, $\mathrm{m}_{\mathrm{t}}$, the economies of scale benefit is either reduced to reflect lower production or forgone altogether.

\subsection{A valuation example ${ }^{23}$}

The XDMP project structure model can be demonstrated with a valuation exercise for an open pit operation focused on a disseminated porphyry mineral deposit. The mine can currently extract 3.2 million tonnes (9000 tonnes per day for 350 days per year) of ore and waste per year and annually process 1.6 million tonnes of ore at the mill. Mining operations are focused on the HG Zone, a high-grade section that contains 14.2 million tones of ore with an average grade of $0.9 \%$ mineral.

Exploration has recently delineated a low-grade satellite zone (called the LG Zone) that contains 12.6 million tonnes of ore with an average grade of $0.6 \%$ mineral. This zone is potentially valuable but it is unclear how it should be developed. Management recognizes that there are competing development strategies for the LG Zone and that the dominant strategy may change with the mineral price. They also realize that they may revise previously made decisions in response to new information at their half-year policy review meetings.

\section{Economic environment}

The real long-term riskfree interest rate is known and a constant 3.0\%. Mineral price uncertainty follows the stochastic process presented in equation 1 for which the annual standard deviation (volatility) is $20 \%$ and the price median growth rate is zero. The annual price of mineral risk, or the additional return for each unit of price volatility, is 0.25 . In other words, the risk-adjustment for holding the mineral is $5 \%$ per annum, which is calculated as the product of the annual standard deviation and the annual mineral price of risk.

${ }^{23}$ A detailed discussion of this example can be found in Samis (2000) that includes sensitivity analysis and the influence of geological uncertainty. 


\section{$5^{\text {th }}$ Annual International Conference on Real Options - Theory Meets Practice \\ Los Angeles, California,United States, 13 and 14 July 2001.}

The mine is valued using both non-reverting (NREV) and reverting (REV) forms of the stochastic process so that the influence of price process characteristics can be observed. ${ }^{24}$ The reverting price process has a half-life of three years so that the reversion factor is 0.231 . The primary difference between the two versions of the price process is the manner in which the magnitude of price uncertainty increases over time. When price follows an NREV process, uncertainty grows at a constant rate so that both the expected and forward (i.e. risk-adjusted) mineral prices change at a constant rate through time. When price follows a REV process, uncertainty increases at a decreasing rate due to market forces pulling the mineral price towards a long-term market equilibrium. Long-term expected and forward mineral prices change less in any given time period than shorter-term expected and forward prices when the mineral price follows a REV process (called the Samuelson (1965) effect).

\section{Current HG Zone production plan}

The HG Zone has enough reserves to support mining operations for nine years at an annual milling rate of 1.6 million tonnes of ore. Annual operating costs are $\$ 18.7$ million per year or $\$ 11.87$ per tonne of ore milled. Given a HG Zone grade of $0.9 \%$, the HG Zone can produce 15.6 million pounds of mineral annually at an average cost of $\$ 0.60$ per pound. If the LG Zone is not developed, the mine is closed when HG Zone is exhausted. Closure costs include a $\$ 40.0$ million charge to cleanup the mine site, a $\$ 1.5$ million charge for abandoning project capacity infrastructure, and $\$ 3.2$ million expenditure for retrenching mine personnel.

\subsection{LG Zone development proposals and other sources of flexibility}

There are two competing development strategies for the LG Zone. The first strategy starts LG Zone development so that ore is simultaneously produced from both the HG and LG Zones for at least part of the project time horizon. This is a parallel development strategy in which the LG Zone is a source of expansion production. The second strategy begins LG Zone development so that LG Zone ore is available immediately after the HG Zone is exhausted. This is a sequential development strategy in which the LG Zone is considered a source of replacement reserves.

The LG Zone production plan and its development requirements (e.g. pre-stripping, access roads) are common to both strategies. The LG Zone can support annual production of 1.6 million tonnes of ore

\footnotetext{
${ }^{24}$ See Salahor (1998) and Laughton and Jacoby (1993) for a discussion of NREV and REV price process characteristics.
} 


\section{$5^{\text {th }}$ Annual International Conference on Real Options - Theory Meets Practice \\ Los Angeles, California,United States, 13 and 14 July 2001.}

(10.4 million pounds) once a $\$ 22.8$ million zone development program is completed. When the LG Zone is mined on its own, the operating cost is $\$ 18.6$ million per annum or $\$ 0.90$ per pound of mineral.

\section{Strategy 1: LG Zone as Production Expansion}

The LG Zone can be developed any time prior to the near exhaustion of the HG Zone. In addition to zone development expenditure, the mine's capacity infrastructure must also be expanded to handle additional production from the LG Zone. This capacity can be built with a one year expansion program costing $\$ 12.8$ million per half-year ( $\$ 25.6$ million total). Further, a $\$ 1.3$ million hiring charge is incurred for expanding the workforce when production starts in the LG Zone. These expansion costs are offset by the combined benefits of receiving LG Zone production earlier and the economies-of-scale generated by doubling ore production. In this example, the economies-of-scale benefits are $17.5 \%$ so that the operating cost of combined HG and LG Zone production is $\$ 30.865$ million per annum (an average cost of $\$ 0.60$ per pound; without economies of scale, the average cost of dual zone production is $\$ 0.75$ per pound).

The site cleanup cost remains $\$ 40.0$ million. However, employee retrenchment and capacity shut-down costs are now $\$ 5.127$ million and $\$ 2.5$ million respectively since additional personnel and mineral processing infrastructure are needed to handle increased mine production. Note that the employee retrenchment costs may be incurred at different times if the two ore zones are exhausted on different dates.

\section{Strategy 2: Production replacement development of the LG Zone}

Exhaustion of the HG Zone and the start of LG Zone production are synchronized when LG Zone development starts with one year of HG Zone reserves remaining. If LG Zone development is started at this time, the labor force and capacity infrastructure (i.e. mine rolling stock, mill grinding and floatation capacity) can be transferred to the LG Zone. Additional capital expenditure is only necessary for LG Zone development; no outlays are required to expand the mine's capacity infrastructure. Mine closure costs are the same as those incurred for closing the mine when the HG Zone is depleted but they are delayed until the LG Zone is exhausted.

\section{Other sources of management flexibility}

If both zones are producing, management has the option of temporarily closing one of the zones in response to low mineral prices. Management can reduce or avoid operating losses with this option by 


\section{$5^{\text {th }}$ Annual International Conference on Real Options - Theory Meets Practice \\ Los Angeles, California,United States, 13 and 14 July 2001.}

incurring a downsizing cost. In this example, the cost of temporarily closing one zone (when two zones are producing) includes a $\$ 0.2$ million transition cost and a retrenchment charge of $\$ 1.9$ million. Management also must decide on an appropriate excess capacity management policy. If the probability of a future price increase is large enough, excess capacity levels can be maintained with only one zone operating with an under-utilized capacity charge of $\$ 1.2$ million per production period. Alternatively, management can avoid this charge by irrevocably abandoning excess capacity with a $\$ 1.5$ million capacity abandonment charge or by temporarily closing excess capacity with a $\$ 0.3$ million charge. If management elects to temporarily close capacity, they can retain the option to re-opening the mothballed capacity by paying a $\$ 0.2$ million closed capacity maintenance fee in each period and a $\$ 3.0$ million rehabilitation charge when the capacity is re-opened.

Finally, the mine may be irrevocably abandoned at any time. The total abandonment cost includes the fixed site cleanup cost of $\$ 40.0$ million, employee retrenchment costs that are dependent on the number of employees on site and a capacity abandonment cost that is a function of the project's capacity state. The retrenchment charge is $\$ 3.2$ million if one zone is producing at the time of abandonment and it is $\$ 5.1$ million if both zones are producing at abandonment. Note that abandonment is the only form of management flexibility available once the HG Zone is depleted.

\subsection{Valuation Results}

Project net present value (NPV) and operating policy is then calculated using the XDMP project structure model with the MAP method. For comparison purposes, mine NPV is calculated using DCF and MAP valuation methods for three different FPPs: 1) exhaust the HG Zone and then close the mine; 2) expand production immediately by developing the LG Zone and then close the mine when both zones are depleted; and 3) start LG Zone production after the HG Zone is depleted and then close the mine when the LG Zone is exhausted. ${ }^{25}$

\section{Project value}

A DCF NPV for each FPP was calculated with a constant $10 \%$ risk-adjusted discount rate (RADR) and a current mineral price of $\$ 1.00$ per pound. Operating costs, transition costs, and capital expenditures were subtracted from expected revenue to generate a net cash flow. Table 1 presents the DCF NPVs. With

\footnotetext{
${ }^{25}$ Note that each FPP is just one of many possible operating policies that are part of the XDMP model.
} 


\begin{tabular}{|l|c|c|}
\hline \multirow{2}{*}{ Project design } & \multicolumn{2}{|c|}{ Project value (\$ million) } \\
\cline { 2 - 3 } & NREV price model & REV price model \\
\hline FPP project structure (DCF valuation method; no abandonment available) \\
\hline HG only production. & 79.522 & 63.498 \\
HG + Early development of LG. & 88.793 & 62.164 \\
HG + Late development of LG. & 106.589 & 71.368 \\
\hline FPP project structure (MAP valuation method; no abandonment available) & 32.163 \\
\hline HG only production. & 19.304 & 39.509 \\
HG + Early LG development. & -4.616 & 20.967 \\
HG + Late LG development. & 41.019 & 40.185 \\
\hline XDMP and FPP project structure (MAP valuation method; abandonment available) & 32.827 \\
\hline HG only production. & 35.036 & 38.246 \\
HG + Early LG development. & 52.945 & 42.302 \\
HG + Late LG development. & 56.616 & \\
XDMP model. & \multicolumn{2}{|c|}{} \\
\hline
\end{tabular}

Table 1. Mine values calculated using DCF and MAP methods (current mineral price $=\$ 1.00 /$ pound). ${ }^{26}$

both price models, the DCF results indicate that the best investment policy is to delay LG Zone development until the HG Zone is depleted.

Table 1 also includes two sets of MAP project NPVs calculated for the FPPs. The first value set corresponds to FPP project structures in which abandonment is not permitted. This value set indicates that the most prudent operating policy in either price environment is to mine the HG Zone until it is exhausted and then close the mine. Late development of the LG Zone is the least favorable strategy because the cash flows generated by the stand-alone LG Zone operation are highly leveraged. When the LG Zone is developed early, the expense of adding capacity is only partially offset by the economies-ofscale benefit associated with doubling mill production. The second MAP value set for the FPPs includes the continuous option to abandon the mine. Each FPP increases in value (substantially with a NREV price process) when management is able to limit downside losses by abandoning the project. When price

\footnotetext{
${ }^{26}$ Note that the price medians of the NREV and REV price processes are the equal but the expected prices of the processes are different. This convention ensures that the mine value in a REV price environment is not dependent upon calendar time.
} 


\section{$5^{\text {th }}$ Annual International Conference on Real Options - Theory Meets Practice \\ Los Angeles, California,United States, 13 and 14 July 2001.}

follows a NREV process, the most valuable FPP is late development of the LG Zone. In a REV price environment, the most valuable FPP remains closing the mine upon exhaustion of the HG Zone.

Mine value is then calculated using the XDMP model and the MAP framework in which management has a full set of operating alternatives. When price follows a NREV model, the MAP NPV increases by $\$ 3.7$ million (a 6.9\% increase) when compared to the most valuable FPP with abandonment. Mine MAP NPV increases by $\$ 2.1$ million (a 5.3\% increase) when compared to the most valuable FPP within a REV price environment.

The LG Zone is shown to add value when either the DCF or MAP valuation framework is used. However, these methods show a wide divergence in calculated mine value due to different assessments of the influence of operating leverage on project risk. The influence of operating leverage on project risk enters the DCF valuation process through a RADR set by the project analyst. Both expected revenues and known operating costs are discounted at the same RADR. The MAP method, however, applies a risk adjustment only to the uncertain cash flow component (in this case, mineral price and, by extension, revenue) such that an explicit risk-adjusted operating profit can be calculated. A time discount is then applied to determine a MAP NPV of the cash flow. In this example, the DCF method over-estimates the value of the project because the ad-hoc RADR provides an insufficient adjustment for operating leverage.

Both valuation methods indicate that the low-grade development decision should be deferred when the current mineral price is $\$ 1.00$ per pound. However, this result is deceptive since the MAP investment recommendation is sensitive to changes in correlation between mineral price uncertainty and general macro-economic uncertainty. This sensitivity may cause the MAP method to produce a different investment signal than the DCF method. In this example, if mineral price correlation is decreased, the MAP method may change its investment recommendation to developing the LG Zone early. The DCF method would fail to register this change in project risk unless management makes a conscious choice to reduce the $\mathrm{RADR}^{27}$

${ }^{27}$ A change in correlation between mineral price uncertainty and general macro-economic uncertainty does not affect the trajectory of the expected mineral price. It only affects the magnitude of the MAP risk adjustment to the expected mineral price. 


\section{$5^{\text {th }}$ Annual International Conference on Real Options - Theory Meets Practice \\ Los Angeles, California,United States, 13 and 14 July 2001.}

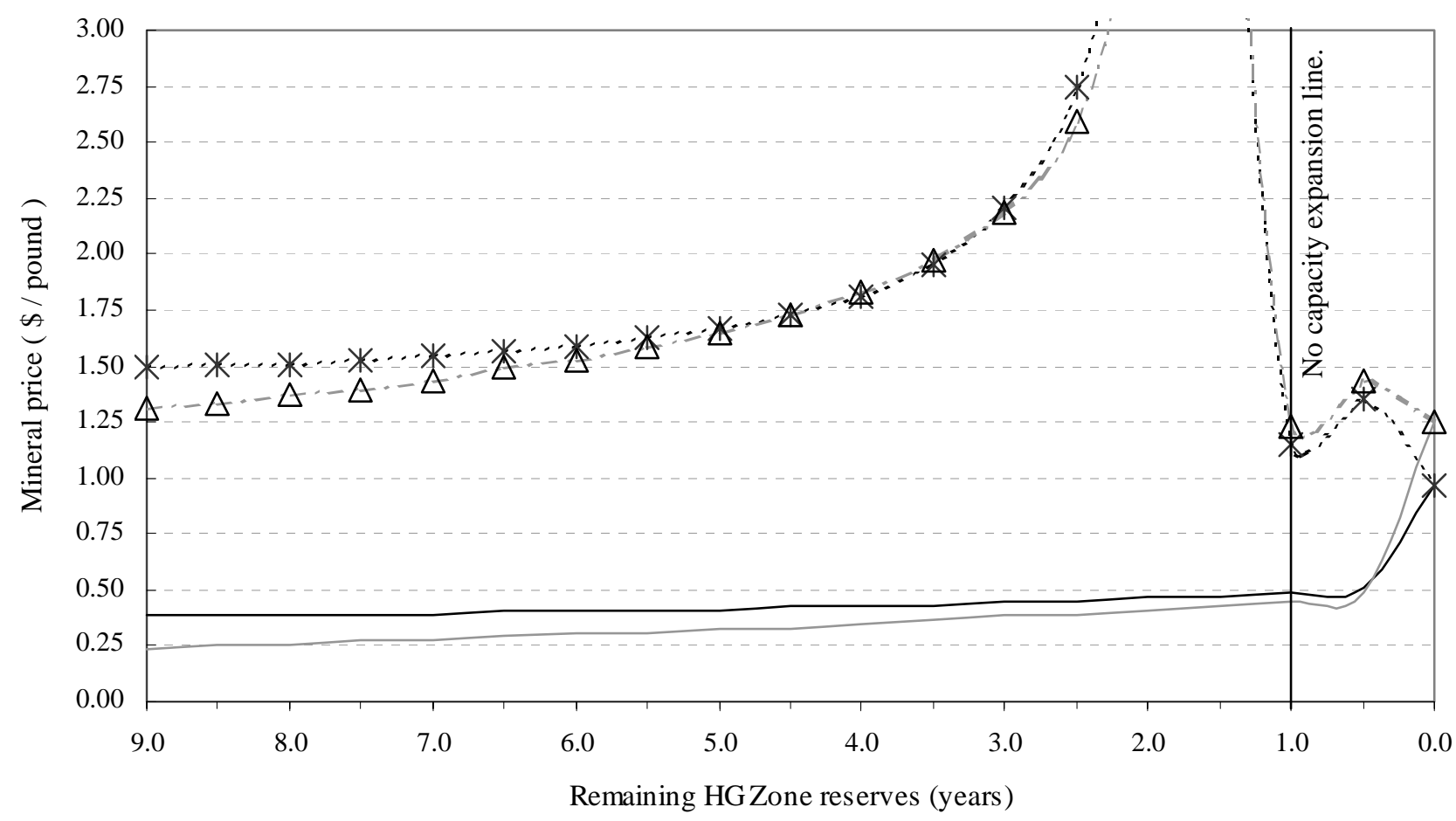

..*... LGdevelopment (NREV) — Abd. (NREV) - - - LGdevelopment (REV)

Abd. (REV)

Figure 2. LG Zone development and project abandonment boundary (NREV and REV price processes).

\section{$\underline{\text { LG Zone development - the mine expansion decision }}$}

Prior to LG Zone development, mine operating policy is delineated by an initial LG Zone development boundary and the abandonment boundary. Figure 2 outlines these boundaries for each price process: black-line coloring is used to indicate the NREV process boundaries and the grey-line coloring are used to indicate the REV process boundaries. The development boundary is delineated with a dashed line and data markers. The data markers are used to indicate the discrete times (X-axis, measured in terms of remaining HG Zone reserves) at which the LG Zone development option can be exercised. At these times, it is optimal for management to begin developing the LG Zone if the mineral price (Y-axis) is above this marker. LG Zone development is deferred if the mineral price is below the marker but above the abandonment price (indicated by the lower solid line). The project is abandoned immediately if the mineral price ever drops below the solid abandonment boundary.

A vertical "no capacity expansion line" is included to show when exercising the LG Zone development option does not require capacity expansion. At this line, capacity expansion is a non-issue because the 


\section{$5^{\text {th }}$ Annual International Conference on Real Options - Theory Meets Practice \\ Los Angeles, California,United States, 13 and 14 July 2001.}

HG Zone will be exhausted before the LG Zone is ready for production. Prior to the "no capacity expansion line", the LG Zone development boundary rises as the HG Zone is depleted due to the decreasing benefits of dual zone production. These benefits justify the investment in capacity expansion; as the dual zone production horizon decreases (and thus the benefits), the mineral price must rise further to offset the additional investment in capacity. After the "no capacity expansion line", the LG Zone development boundary decreases drastically because no capacity expansion is required.

The project is abandoned immediately if the mineral price drops below the solid line at any time. This boundary rises slowly because the probability that the mineral price will be at levels such that the project becomes profitable is decreasing as the HG Zone is exhausted. The abandonment boundary rises sharply immediately before exhaustion of the HG Zone because management is being confronted with the prospect of developing a new ore reserve in which operating leverage is much greater.

The LG development option can also be assessed by the various payoff profiles produced by the FPP and XDMP project structure models. Figures 3a and $\mathbf{3 b}$ illustrate these profiles for NREV and REV price processes when there is 9 years of HG Zone reserves remaining. They show that in high and low price environments, the payoff profile of the XDMP model is closely tracked by one of the FPP payoff profiles. This implies that an experienced analyst can reduce the complexity of the XDMP model with several well-chosen FPPs that include project abandonment in some situations when only a project value is needed. However, these figures also show that the XDMP model is preferred when an expansion price signal is required. The XDMP model indicates that immediate LG Zone development should occur if the current mineral price is greater than $\$ 1.49$ (\$1.31) per pound when the price follows the NREV (REV) diffusion; whereas the FPP model signals immediate development when the mineral price is above $\$ 1.25$ (\$1.17) for a NREV (REV) price process. The FPP model significantly underestimates the LG Zone development price because it does not incorporate the opportunity cost associated with exercising the LG Zone development option. This opportunity cost is created because the opportunity to develop the LG Zone in the future is given up when zone development starts. 


\section{$5^{\text {th }}$ Annual International Conference on Real Options - Theory Meets Practice Los Angeles, California,United States, 13 and 14 July 2001.}

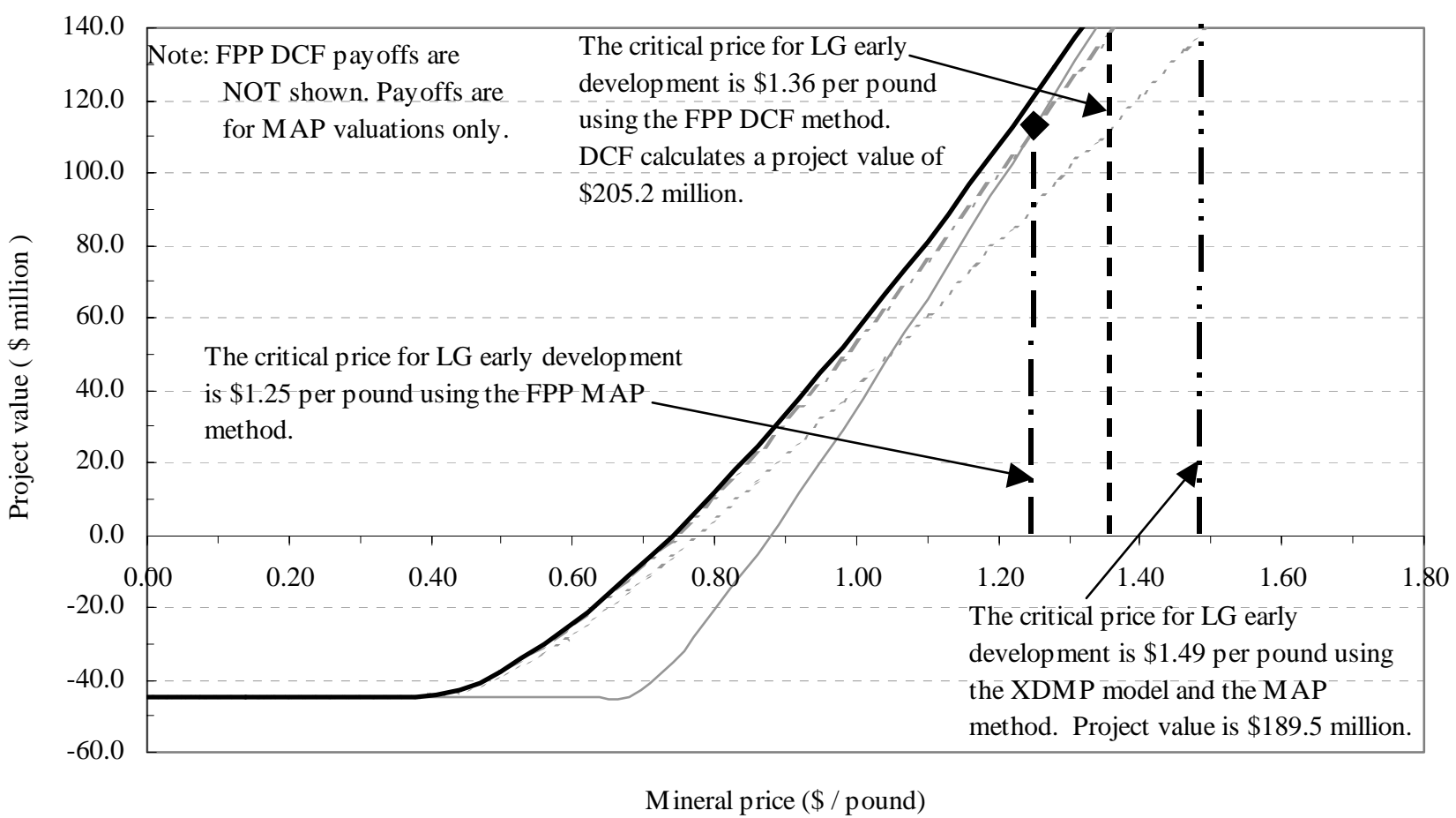

…. HGonly FPP — Early LGdev. FPP _. - Late LGdev. FPP $\quad$ XDMP model

Figure 3a. Mine value payoffs for FPP and XDMP models (NREV price process).

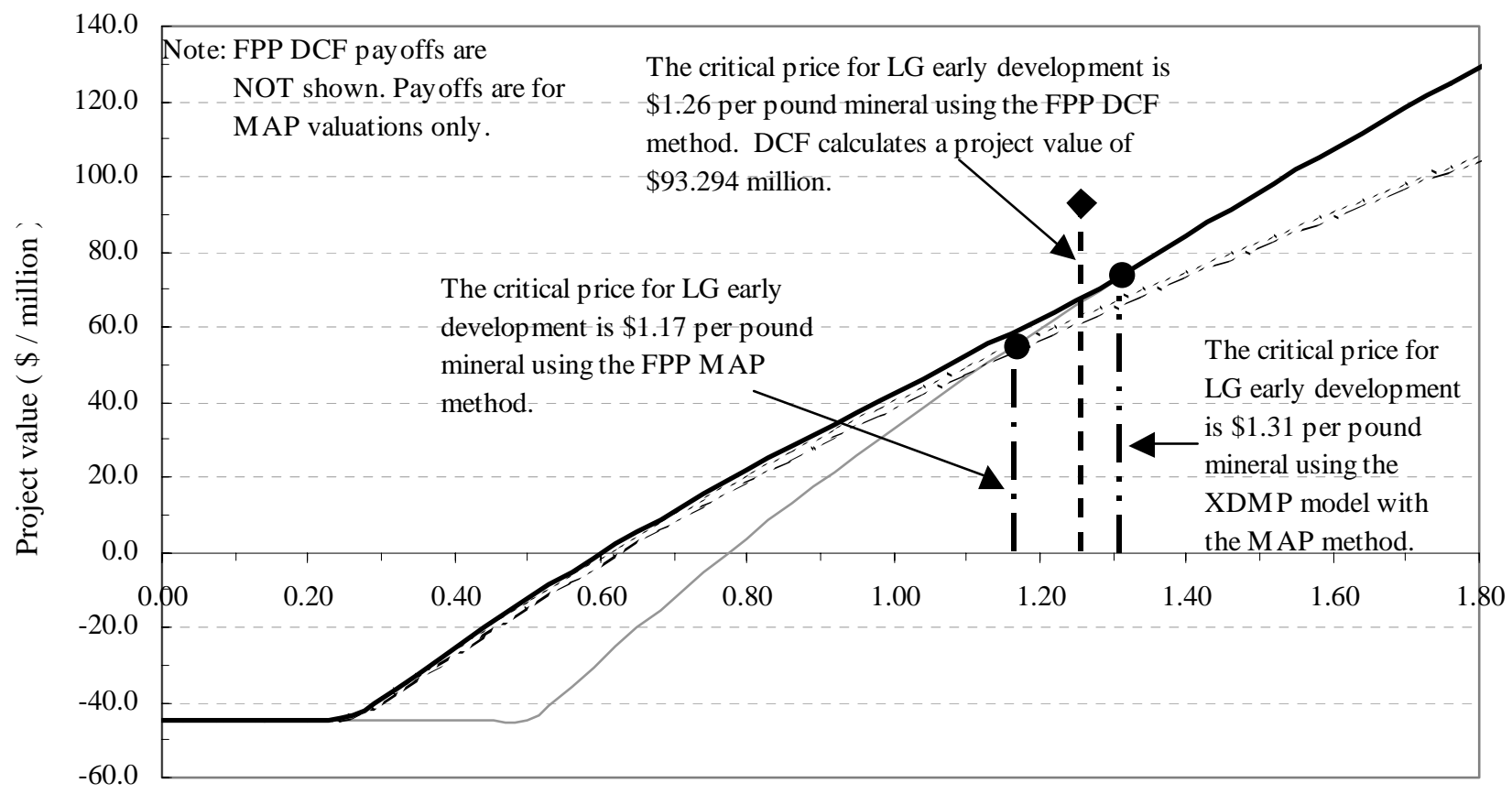

Mineral price (\$ / pound)

.......HGonly FPP — Early LGdev. FPP - - - - Late LGdev.t FPP $\quad$ XDMP model

Figure 3b. Mine value payoffs for FPP and XDMP models (REV price process). 


\section{$5^{\text {th }}$ Annual International Conference on Real Options - Theory Meets Practice \\ Los Angeles, California,United States, 13 and 14 July 2001.}

\section{Temporary closure of individual zones}

Individual zone closure is a possible low-mineral price operating strategy that appears to be implemented more often in the mining industry than full temporary mine closure. The two-zone mine example presented in this paper can be used to study the importance of selective zone closure by varying the quality of the LG Zone. The following results represent the expanded project's zone closure policy in a $\mathrm{REV}$ price environment ${ }^{28}$ when the $\mathrm{LG}$ Zone is brought into production at the earliest possible time (i.e. LG Zone development is started immediately and initial production is not delayed).

Figures $\mathbf{4 a}, \mathbf{4 . b}, \mathbf{4 c}$ and $\mathbf{4 d}$ display zone closure policies for LG Zone mineral concentrations of $0.42 \%$, $0.51 \%, 0.60 \%$ and $0.69 \%$. In each figure, the optimal policy is to close one of the zones at management decision points when the mineral price is below the data marker on the dashed line. Figure 4a shows that the preferred policy is LG Zone closure with capacity abandonment when LG Zone's grade is $0.42 \%$. This policy is optimal in low price environments with the dual-zone production horizon until the reserves of each zone are almost exhausted. Figure 4b shows that LG Zone closure policy is associated with temporary capacity closure when the remaining reserves of each zone are large and the LG Zone grade is $0.51 \%$. This association changes to capacity abandonment as dual-zone mining continues. At highly reduced levels of zone reserves, LG Zone closure ceases to be an attractive alternative to project abandonment. Figures $\mathbf{4 c}$ and $\mathbf{4 d}$ presents the individual zone closure policy when the LG Zone grade is $0.60 \%$ and $0.69 \%$. At these LG Zone grades, the preferred operating strategy in low mineral price environments with large reserves is closure of the HG Zone and continued production in the LG Zone. Closure of the LG Zone with temporary capacity shut-down is the preferred policy in only very select situations.

Selective zone closure is driven by the difference between the unit operating $\operatorname{costs}^{29}$ of dual-zone production and those of each single-zone production strategy. This difference can be negative (dual-zone unit costs less than the unit costs of both single-zone strategies) or positive (dual-zone unit costs greater than unit costs of the HG Zone production strategy) depending upon the qualities of the HG and LG Zones. In this example, the unit operating cost difference is positive when the LG Zone grade is below $0.60 \%$ and negative above this point.

\footnotetext{
${ }^{28}$ Temporary closure policy of select zones for the NREV price environment can be found in Samis (2000).

${ }^{29}$ Unit mineral operating costs are calculated as a total operating costs divided by the quantity of mineral produced.
} 


\section{$5^{\text {th }}$ Annual International Conference on Real Options - Theory Meets Practice Los Angeles, California,United States, 13 and 14 July 2001.}

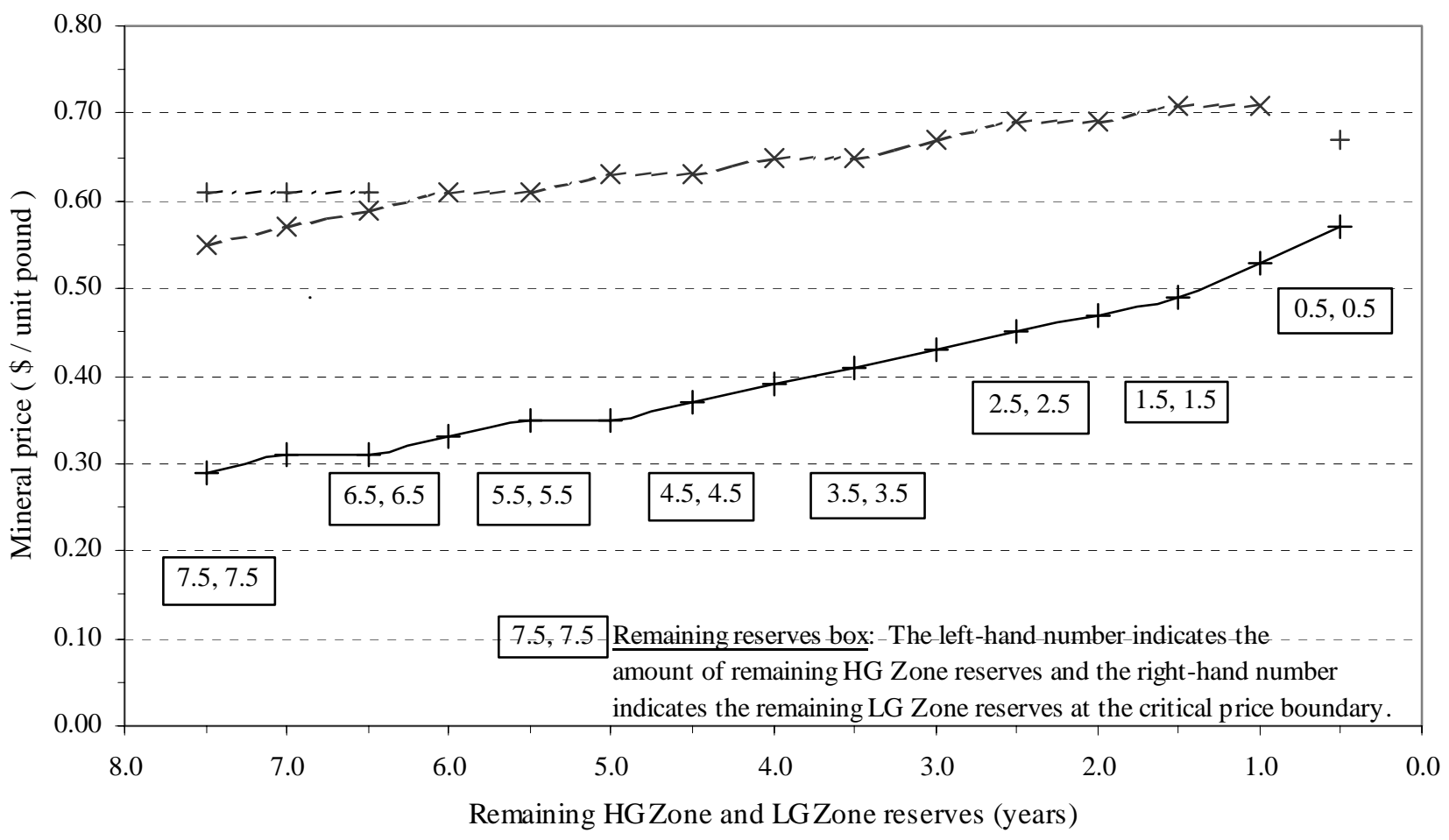

-?+- HG only/close capacity

- - X - HGonly/abandon capacity

Abandonment

Figure 4a. Zone closure boundaries for an expanded project $(\mathrm{LG}=0.42 \%)-\mathrm{REV}$ model.

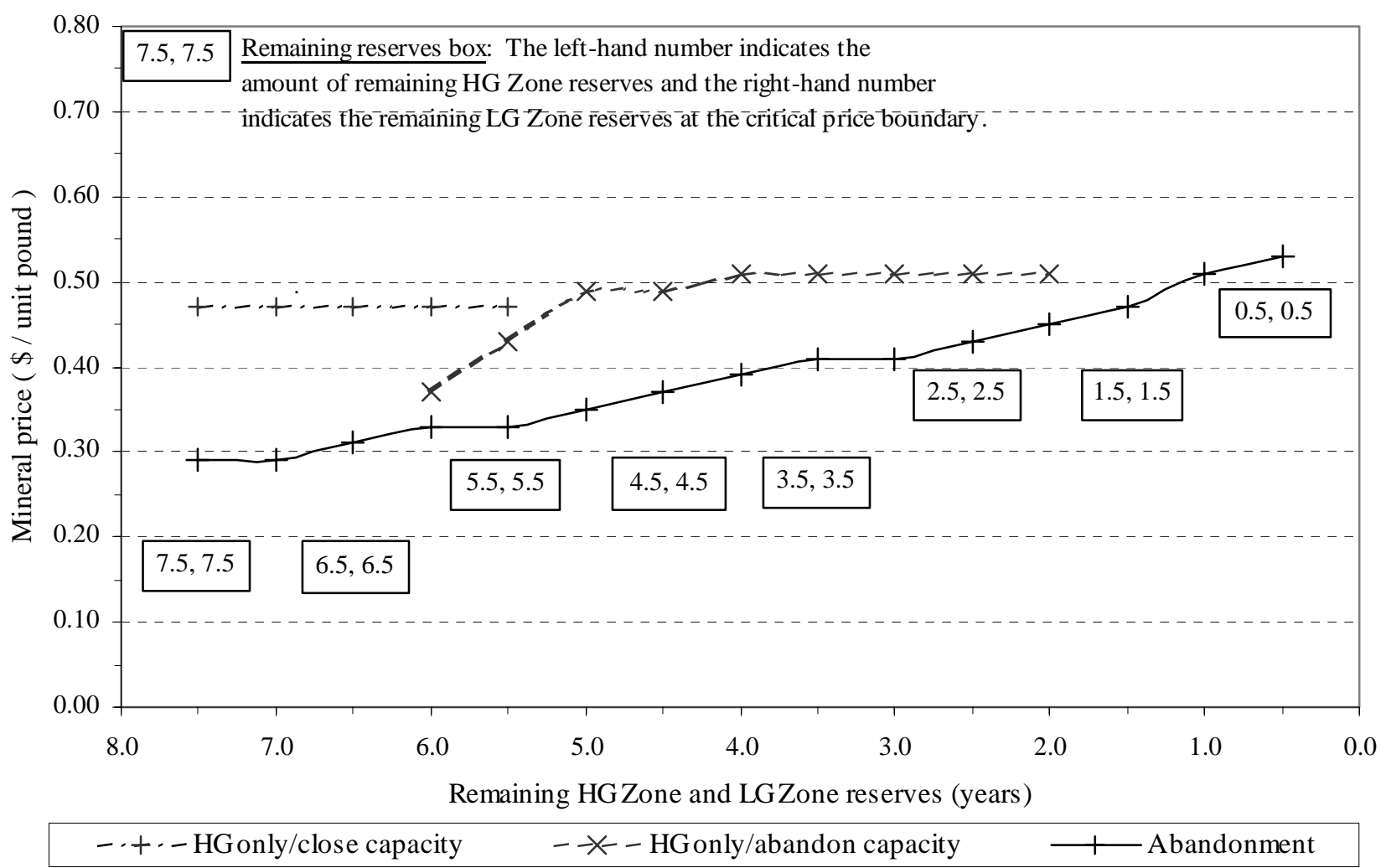

Figure 4b. Zone closure boundaries for an expanded project $(\mathrm{LG}=0.51 \%)-\mathrm{REV}$ model. 
$5^{\text {th }}$ Annual International Conference on Real Options - Theory Meets Practice

Los Angeles, California,United States, 13 and 14 July 2001.

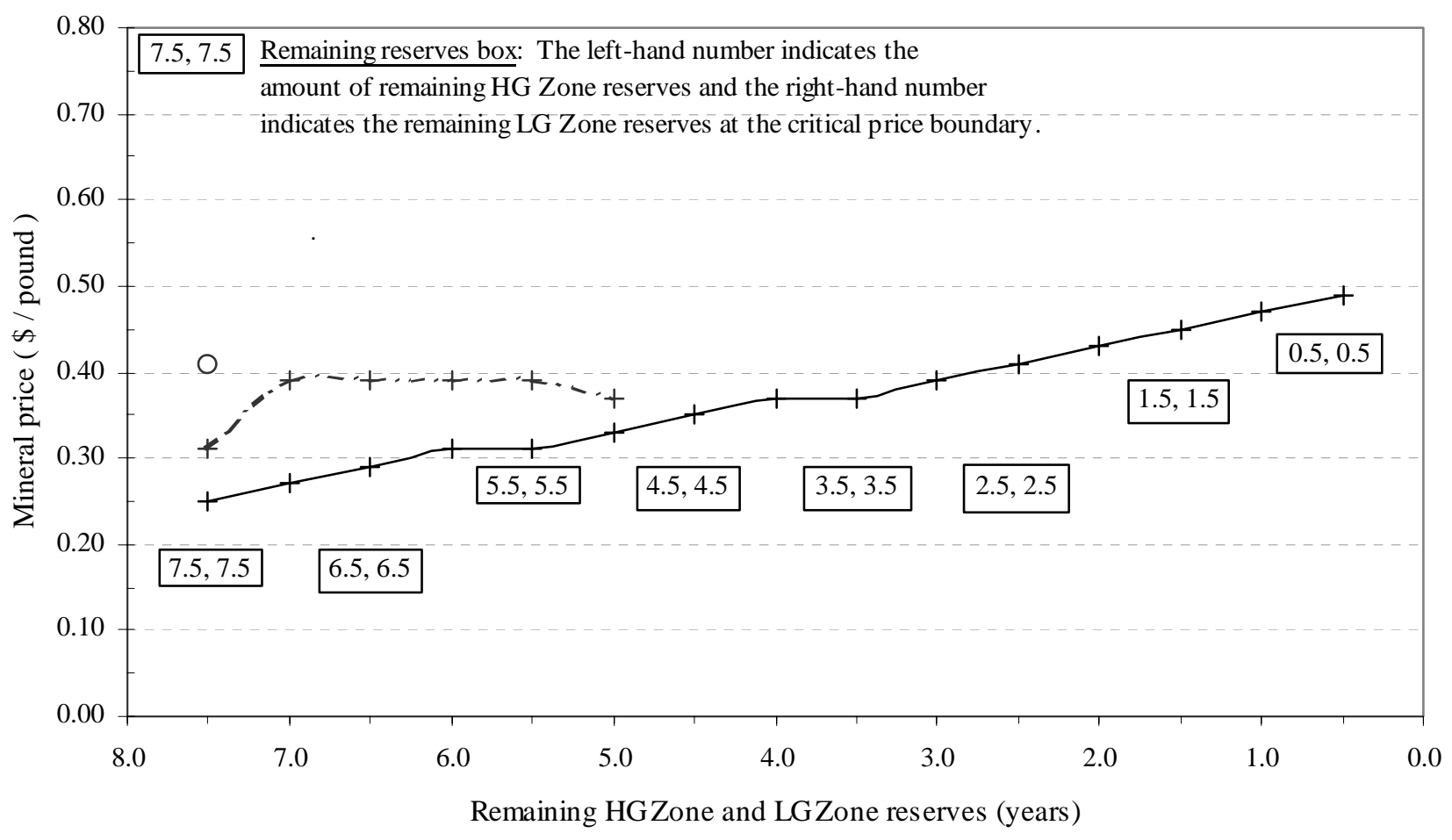

..... LGonly/close capacity _-.+-HGonly/close capacity _ _ Abandonment

Figure 4c. Zone closure boundaries for an expanded project $(\mathrm{LG}=0.60 \%)-\mathrm{REV}$ model.

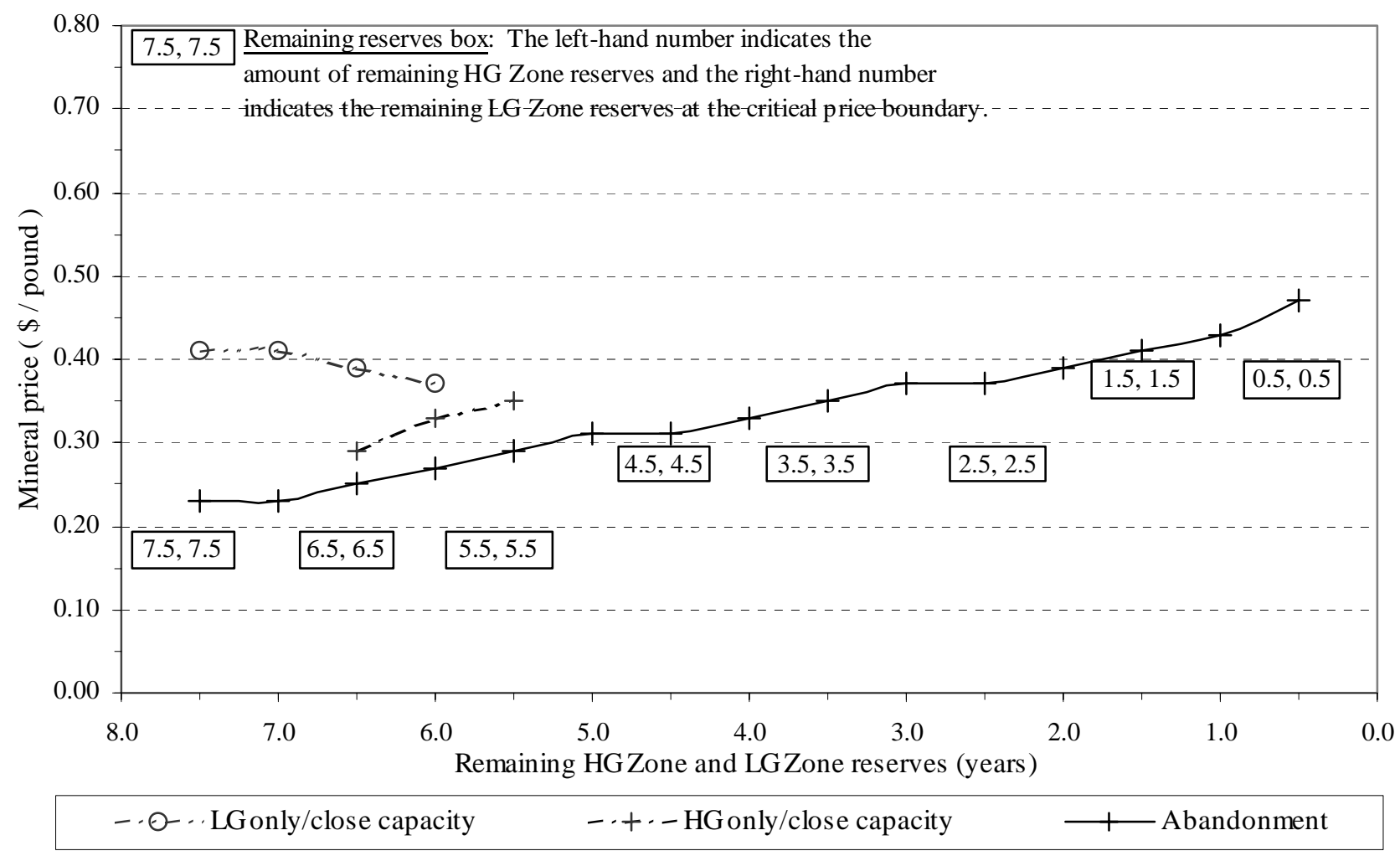

Figure 4d. Zone closure boundaries for an expanded project $(L G=0.69 \%)-R E V$ model. 


\section{$5^{\text {th }}$ Annual International Conference on Real Options - Theory Meets Practice \\ Los Angeles, California,United States, 13 and 14 July 2001.}

There is an incentive to close the LG Zone when unit operating cost differences are positive since closing this zone generates operating cost savings. For example, if the LG Zone grade is $0.51 \%$ and there are 7.5 years of HG Zone reserves (see Figure 4b), management closes the LG Zone and excess capacity when the mineral price drops below $\$ 0.48$. The project's total operating losses change from $\$ 3.693$ million when both zones are producing to $\$ 1.860$ million when only the HG Zone is operating. Figures $4 a$ and 4b show that the zone closure boundary rises as the magnitude of the unit operating cost difference increases. These figures also show that the size of zone reserves influences the zone closure boundary. A larger reserve base increases the incentive to close the LG Zone because such a base provides a longer production time horizon over which to generate the cost savings necessary to offset zone closure costs. In this example, the zone closure option is important over the full dual-zone production horizon when LG Zone grade is $0.42 \%$ while it is only important over part of this horizon when the LG Zone grade increases to $0.51 \%$.

Figures 4c, and 4d show selective zone closure boundaries, in a REV price environment, when there is negative unit cost difference between dual-zone and HG Zone production. The zone closure boundaries presented in these figures differ from those in Figures $4 \mathbf{a}$ and $\mathbf{4 b}$ because there is a boundary that indicates closure of the HG Zone instead of the LG Zone. This behavior indicates that, at large reserve levels and higher LG Zone grades, the optimal policy is to preserve the high quality reserves by closing the HG Zone. In this situation, the operating losses created by mining the LG Zone are offset by possible higher profits gained by re-opening the high-grade zone in higher mineral price environments. Sagi (1998) has previously shown that, in REV price environments, management may find it optimal to decrease the project's cutoff grade in response to low mineral price. This action was justified by the observation that the expectation of future price increases, derived from the mineral price reverting to the long-term equilibrium, creates an incentive for management to preserve higher quality reserves until price levels improve.

Temporary closure of all ore zones is also a possible strategy for low mineral price situations (Brennan and Schwartz, 1985). The inclusion of full project closure as a management option would affect the zone closure boundaries delineated here since it would be the preferred strategy at some prices where project abandonment or selective zone closure is now preferred. In particular, it may have its greatest impact on the strategy of closing the HG Zone in low REV price environments because full project closure may dominate high-grade zone closure in all low price outcomes (i.e. it is potentially better to preserve the 


\section{$5^{\text {th }}$ Annual International Conference on Real Options - Theory Meets Practice \\ Los Angeles, California,United States, 13 and 14 July 2001.}

reserves of both the HG and LG Zones until prices improve). However, it is not considered in this example because the dynamics and costs of either full or temporary project closure in the mining industry have not been studied in detail. ${ }^{30}$ Cost curves exist to estimate the costs associated with building and operating mining projects (e.g. O'Hara, 1980) but there do not appear to be similar such tools for estimating the costs associated with either maintaining or abandoning excess capacity. Given the lack of closure cost data, it was considered better to observe selective zone closure in isolation with estimated cost figures than to obscure the role of selective zone closure with an ill-conceived project closure model that incorporated both partial and full closure.

\subsection{Conclusion}

This paper presented the XDMP project structure model that extends the ability of mining analysts to investigate operating policy in a valuation exercise. In this model, a mining project is modeled as a real asset portfolio in which the zones of the mineral deposit, delineated on the basis of quality, location and size, take the role of portfolio components. Management operates the project on a discrete basis by selecting some zones for current development and production activities and others for inactivity while managing the project's ability (i.e. capacity) to extract and process mineral. This approach allows project costs to be calculated in detail on the basis of project state and to differentiate between capital that is used in fixed applications such as zone development and capital that has more flexible uses such as mineral processing capacity that can handle production from any deposit zone. It also incorporates the influence of geological structure on operating policy by allowing management to consider strategies that make use of the mineral deposit's heterogeneity.

The XDMP model was demonstrated with a two-zoned mining example that considered parallel (capacity expansion) zone development versus sequential zone development, selective zone closure and capacity management options. The ability to select operating policies that exploit geological structure was found to add significant but not spectacular value when compared to scenario-based MAP valuation models that ignore this ability. However, the XDMP model also showed that these conventional models signal policy

\footnotetext{
${ }^{30}$ It has been this author's experience that temporary closure costs and the strategy of temporary mine closure are not considered an important aspect of mine valuation until low mineral prices force the issue. A few years ago, the author was part of a general discussion regarding real options at a large mining company where real options was dismissed by senior management as irrelevant since, in their opinion, temporary closure was not a serious consideration for mines that were not exploiting small streambed (placer) deposits. Moel and Tufano (forthcoming) have completed econometric research that demonstrate that temporary mine closure is a viable strategy in the mining industry but they do not provide an indication of the costs associated with this action.
} 


\section{$5^{\text {th }}$ Annual International Conference on Real Options - Theory Meets Practice \\ Los Angeles, California,United States, 13 and 14 July 2001.}

change involving capital investment at much lower prices, which may lead to incorrect investment decisions. In addition, the XDMP model provided greater insight into project operating policy that scenario-based MAP models would have difficulty highlighting, such as selective zone closure in lowmineral price environments.

\section{Acknowledgments}

The author gratefully acknowledges research support while completing his doctorate from an FCAR grant obtained through Université Laval and several earlier grants from the Department of Mining and Mineral Process Engineering at the University of British Columbia. He would like to thank Dr. David Laughton of the University of Alberta, Professor Richard Poulin of Universite Laval, and Dr. Jacob Sagi of the University of California at Berkeley for their comments and suggestions while conducting his research. He would also like to thank Dr. Scott Dunbar, Dr. Alan Hall and Professor Malcolm Scoble of the University of British Columbia for their support during his Ph.D. studies. Any errors or omissions in this paper are the sole responsibility of the author.

\section{Bibliography}

Brennan, M. and E. Schwartz (1985). "Evaluating natural resource investment." Journal of Business 58(2): pp. 135-157.

Childs, P. (1995). Capital Budgeting for Interrelated Projects. Unpublished Ph.D. dissertation, Graduate School of Business, University of Wisconsin-Madison. Madison, WI: 129p.

Childs, P., S. Ott and A. Triantis (1998). "Capital budgeting for interrelated projects: A real options approach." Journal of Financial and Quantitative Analysis 33(3): pp. 305-334.

Chorn, L. and P. Carr (1997). The value of purchasing information to reduce risk in capital investment projects. Hydrocarbon economics and evaluation symposium, Dallas, TX, Society of Petroleum Engineers.

Cormen, T., C. Leiserson and R. Rivest (1997). Introduction to Algorithms. Cambridge, MA, The MIT Press: 1028p.

Cortazar, G. and J. Casassus (2000). "A compound option model for evaluating multistage natural resouce investments". Project flexibility, agency and competition - New developments in the theory and 


\section{$5^{\text {th }}$ Annual International Conference on Real Options - Theory Meets Practice Los Angeles, California,United States, 13 and 14 July 2001.}

application of real options. Ed(s): M. Brennan and L. Trigeorgis. New York, NY, Oxford University Press: pp. 205-223.

Dixit, A. (1993). The Art of Smooth Pasting. Princeton, NJ, Harwood Academic Publishers: 72p.

Dixit, A. and R. Pindyck (1994). Investment Under Uncertainty. Princeton, NJ, Princeton University Press: 468p.

Frimpong, S. (1992). Evaluation of Mineral Ventures using Modern Financial Methods. Unpublished Ph.D. dissertation, Department of Mining Engineering, University of Alberta. Edmonton, AB: 211p.

He, H. and R. Pindyck (1992). "Investments in flexible production capacity." Journal of Economic Dynamics and Control 16(3/4): pp. 575-599.

Jacoby, H. and D. Laughton (1992). "Project evaluation: A practical asset pricing method." The Energy Journal 13: pp. 19-47.

Laine, J. (1997). Option valuation of field development projects. Hydrocarbon Economics and Evaluation Symposium, Dallas, TX, Society of Petroleum Engineers.

Laughton, D. and H. Jacoby (1993). "Reversion, timing options and long-term decision-making." Financial Management 22(3): pp. 225-240.

Majd, S., and R. Pindyck (1987). "Time to build, option value and investment decisions." Journal of Financial Economics (18): pp. 7-27.

Mardones, J. (1991). International Investment Contracting with Financial Market Segmentation: Option Valuation of a Copper Mine. Unpublished Ph.D. dissertation, Fletcher School of Law and Diplomacy, Tufts University: $383 p$.

Mardones, J. (1993). "Option valuation of real assets: Applications to a copper mine with operating flexibility." Resource Policy: pp. 51-65.

Milne, A., and A. Whalley (2000). “Time to build, option value and investment decisions': a comment.” Journal of Financial Economics (56): pp. 325-332. 


\section{$5^{\text {th }}$ Annual International Conference on Real Options - Theory Meets Practice Los Angeles, California,United States, 13 and 14 July 2001.}

Moel, A. and P. Tufano (forthcoming). "When are real options exercised? An empirical study of mine closings." Review of Financial Studies.

Mular, A. and R. Poulin (1998). CapCosts: A Handbook for Estimating Mining and Mineral Processing Equipment Costs and Capital Expenditures and Aiding Mineral Project Evaluations. Montreal, Quebec, Canadian Institute of Mining, Metallurgy and Petroleum: 319p.

O'Hara, T. (1980). "Quick Guides to the Evaluation of Orebodies.” CIM Bulletin (February): pp. 87-99.

Palm, S., N. Pearson and J. Read (1986). "Option pricing: A new approach to mine valuation.” CIM Bulletin 79(May): pp. 61-66.

Sagi, J. (1998). "The interaction between quality control and production". Forthcoming in: Innovation and Strategy, Flexibility, Natural Resources and Foreign Investment: New Developments and Applications in Real Options. Ed(s): L. Trigeorgis. New York, NY, Oxford University Press.

Salahor, G. (1998). "Implications of output price risk and operating leverage for the evaluation of petroleum development projects.” The Energy Journal 19(1): pp. 13-46.

Samis, M. and R. Poulin (1996). Valuing management flexibility by derivative asset valuation. 98th CIM AGM, Edmonton, Canada.

Samis, M. and R. Poulin (1998). "Valuing management flexibility: A basis to compare the standard DCF and MAP valuation frameworks." CIM Bulletin 91(1019): pp. 69-74.

Samis, M. (2000). Multi-Zone Mine Valuation Using Modern Asset Pricing (Real Options) Techniques. Unpublished Ph.D. dissertation, Department of Mining and Mineral Process Engineering, University of British Columbia. Vancouver, BC: 161p.

Samuelson, P. (1965). "Proof that properly anticipated prices fluctuate randomly." Industrial Management Review 6: pp. 41-49.

Sick, G. (1989). "Capital budgeting with real options". Monograph Series in Finance and Economics. Stern School of Business, New York University. New York, NY: 81p. 
Smit, H. (1997). "Investment analysis of offshore concessions in the Netherlands." Financial Management 26(2): pp. 5-17.

Smith, J. and K. McCardle (1999). "Options in the real world: Lessons learned in evaluating oil and gas investments." Operations Research 47(1): pp. 1-15.

Trigeorgis, L. (1990). “A real-options application in natural-resource investments.” Advances in Futures and Options Research - Volume 4. JAI Press: pp. 153-164.

Whiting, J., S. Frimpong, and D. Laughton (1993). "Quantification and analysis of mineral venture management alternatives using derivative asset valuation." Innovative Mine Design for the $21^{\text {st }}$ Century. Ed(s): Bawden and Archibald. Balkema, Rotterdam: pp. 205-216. 